Factorization of Verbs: An Analysis of Verbs of Seeing

In 1972, I spent a year at the Institute for Advanced Study, Princeton, as a Guggenheim Fellow. I was invited to join a group of visitors, all interested in various aspects of language. George Miller was heading this group. The other visitors were Phil Johnson Laird, now at Princeton University and Pim Levelt, now at Max Plank Institute, Nijmegen, The Netherlands. It was truly a wonderful year. I was allowed to continue my research in Computational Linguistics and branch out in other directions of my choosing. I continued my work in Mathematical Linguistics, 'testing' it by explaining it to George, Phil, and Pim. These interactions allowed me to formulate a long term program in Mathematical Linguistics (ML). At the same time I was quite attracted by the work on Verbs of Motion that George and Phil had initiated. I thought it might be interesting to look at the Verbs of Seeing from this perspective. George encouraged me very strongly, always reminding me to follow an independent direction. The enclosed manuscript was finished in June 1972, a couple of months before I returned to Penn, where they roped me into the job of the Department Chair for Computer and Information Science at the University of Pennsylvania, a newly created Department. I was 'stuck' in this job for almost 12 years. Over the years, I have talked about this paper and the general topic of lexical decomposition but I never got around to write a long paper on this topic.

In 2009 at a Computational Linguistics (CL) meeting in Boulder, CO, Nicolleta Calzolari and James Pustejovsky at a late evening session in a bar encouraged me to edit and clean up my paper the "Verbs of Seeing" and James even agreed to write with me a "Letter to the Editor" type of paper to which the electronic version of my paper on Verbs of Seeing can be attached, hopefully encouraging the readers to look at the full paper.

The original version of my paper had to be converted to an electronic file. This turned out to be a very tedious job indeed. The original paper was hand typed by me on a mechanical typewriter, some symbols introduced by hand. The task of generating an electronic file from the 1972 file turned out to be a long and tiresome task. The original paper file was converted to a pdf file (with all the hand drawn symbols and figures). This file was then converted to a Word file so that it could be edited easily (?). All this took much longer than expected. Some Sections had to be retyped completely.

In the original version a linguist was referred to by 'he". The "she/he' version was just making its way in 1972. In the current version the she/he problem was avoided!

Aravind K. Joshi

Department of Computer and Information Science and Department of Linguistics

Institute for Research in Cognitive Science

University of Pennsylvania

Philadelphia PA

USA

joshi@seas.upenn.edu 
Aravind K. Joshi

June 1972

\section{FACTORIZATION OF VERBS: AN ANALYSIS OF VERBS OF SEEING*}

1. Introduction

2. Some methodological considerations

2.1 Syntactic and semantic representations

2.2 Syntactic evidence

2.3 Syntactic-semantic evidence: paraphrase and incomplete definition

2.4 Possible lexical items

2.5 Redundancy

2.6 Regularization of predicates

2.7 Semantic evidence

2.8 Psychological evidence

2.9 Abstractness of factors

3. Examples of factorizations

3.1 Nonstative verbs (occur analysis)

3.2 Nonstative analysis (action verbs, do analysis)

3.3 Remind

3.4 Motion verbs

3.5 Miscellaneous

4. Notations and conventions

5. Verbs of seeing

5.1 Introduction

5.2 Criteria for verbs of seeing

5.3 A list of verbs of seeing

5.4 Analysis of some verbs of seeing

5.5 Summary: 5.5.1 List of predicates used in Section 5.4

5.5.2 List of representations

5.5.3 Lexical gaps

6. Other verbs of perception

46

7. References 


\section{Introduction:}

One current issue in linguistics is factorization of vocabulary, in particular, verbs. Factorizations of individual verbs or verbs belonging to certain classes have been proposed recently by several linguists, not necessarily of the same persuasion. Some examples are (see Section 4 for notations and conventions): $\mathrm{V}_{\text {act }}$ : $\operatorname{do}\left(\mathrm{V}_{\text {act }}()\right)$ where $\mathrm{V}_{\text {act }}$ is an action verb, kill : $\underline{\text { cause }}(\mathrm{x}, \underline{\text { become }}(\underline{\text { not }}(\underline{\text { alive }}(\mathrm{y}))))$, remind : perceive $(\mathrm{x}$ $\underline{\operatorname{similar}}(\mathrm{y}, \mathrm{z})$ ), give $: \underline{\text { cause }}(\mathrm{x}$, have $(\mathrm{y}, \mathrm{z}))$ attribute $: \underline{\text { claim }}(\mathrm{x}, \operatorname{make}(\mathrm{y}, \mathrm{z})$ ), etc. (Bierwisch, Harris, Lakoff, McCawley, Postal, Ross, and others). The motivation of a linguist is roughly as follows: To arrive at representations which, on the one hand, have immediate semantic interpretation and, on the other hand, also form the basis for ultimately deriving the surface forms. Thus the system of primitives (and their organization) which he arrives at has to be both semantically and syntactically relevant. This determines the kind of evidence needed (or the methodological considerations involved) in justifying these factorizations.

Recently, Miller (1972 a, b) has made an analysis of the verbs of motion with a view towards setting up a framework for the study of the organization of lexical memory. Some of the evidence used in his study is similar to that of a linguist, reflecting the hypothesis that the linguists' system of primitives has some relevance to the psychological work. Miller also provides some independent support for the psychological validity of his analysis.

A part of this paper (Sections $2.1-2.9$ ) is devoted to a review and a critique of the major methodological considerations involved in justifying such factorizations. These, certainly, are not all of equal weight and also not necessarily independent of each other. But they do characterize the kinds of arguments that have been used. In Section 3, we give some examples of factorization which have appeared in the literature in order to illustrate some of these arguments.

The major part of this paper is devoted to an analysis of some verbs of seeing. By verbs of seeing, we mean verbs which in one of their senses involve visual perception (e.g., see, look, gaze, glance, appear, hide, display, expose, etc.). We use the paraphrastic relationships and incomplete definitions to arrive at a factorization and then at each step we try to muster evidence of the kind discussed in Sections 2.2 - 2.7 to support the factorization. A comparison with the hearing verbs is carried out throughout Section 5 and a brief discussion of other verbs of perception is presented in Section 6.

The notations and conventions appear in Section 4. A reader interested only in the analysis of seeing verbs can skip Sections 2 and 3. 
2. Some methodological considerations:

\subsection{Syntactic and semantic representations:}

The choice of a particular scheme of representation will certainly influence the kind of components we will recognize as well as their organization. A priori, there is no reason to require that the same sort of formal object be used for the syntactic representations as well as for the semantic representations. However, if we want to map the semantic representation onto the syntactic representations i.e., ultimately onto actual sentences, then it is certainly convenient to have the same type of formal object used for both the representations. The generative semanticists make this a basic requirement of the linguistic theory. Thus if the formal object is a phrase structure tree then both the syntactic and semantic representations will be in terms of such trees. Only a single kind of mapping will connect semantic representations and syntactic representations. For example, in the case of phrase structure trees this mapping will be the kind of mapping obtained by a transformational rule. Thus the surface syntactic trees will be deformations of the semantic trees; to be sure, only certain kinds of deformations will be allowed.

Alternative representations are dependency trees or the closely related operator-operand representation both of which can be formally related to the phrase structure tree representation, although there are certain advantages and disadvantages with each one of these representations. It is possible to have even a combination of these representations. In this paper, we will adopt the operator-operand representation (see Section 4).

If we are interested only in the semantic representations then it is certainly not necessary to restrict ourselves to phrase structure trees or dependency trees. Even when we are concerned with mappings of semantic representations onto syntactic representations we should not rule out the possibility of having more than one type of mapping; however, this opens up the question of what other kinds of mappings besides transformations (trees onto trees or structured strings onto structured strings, in general) should be allowed. Very little can be said about this matter at present. It is interesting to note in this context that Fillmore (1971) considers dependency trees with branches also labelled (by case labels, in particular) as suitable objects for semantic representations but then laments the fact that these representations lend themselves least to the view, that the semantic and syntactic representations belong to the same species.

For our present purpose, we'll assume that we have only one type of formal object for the syntactic and semantic representations and therefore only one type of mapping connecting them. The main point here is not that we are making this assumption but rather its implication. That is, this assumption limits our choice of representations and as we said in the beginning the kind of representation we adopt affects considerably the kind of factorization we arrive at.

\subsection{Syntactic evidence:}

While attempting to formulate (syntactic) rules for well-formedness of strings of morphemes, sometimes, one has to postulate elements in the underlying representation which are not phonetically 
manifested. These elements often turn out to be semantically relevant. A well-known example is the underlying you in the representation for imperative sentences. Another example is the underlying do in the analysis of action verbs (Ross 1971). Syntactic evidence pertains only to the distribution of formal syntactic elements i.e., grammatical morphemes. Only such evidence is permissible in establishing the well-formedness of (syntactic) rules. A purely syntactic argument would not use evidence pertaining to paraphrase, ambiguity, etc.

In a purely syntactic argument there is an implied assumption that a sharp distinction can be made between well-formed and ill-formed strings. As is well known, this distinction is far from being sharp. Much of the recent linguistic research depends heavily on looking at rather marginal sentences (perhaps not so marginal for the authors). It is as if many deeper aspects of the structure of language are revealed by considerable stretching of the language. Often one permits a rather marginal sentence $\left(\mathrm{S}_{1}\right)$ as acceptable (and therefore as an evidence for the argument) by exhibiting another sentence $\left(\mathrm{S}_{2}\right)$ which is more readily acceptable and which is a near paraphrase of $\mathrm{S}_{1}$, thus relying not entirely on syntactic evidence.

If elements (i.e., components in the factorization) are postulated in the underlying representation (and which are not phonetically manifested) using syntactic evidence and also relying on some particular semantic relationships (paraphrase and incomplete definition, in particular) then we will say that: the factorization has been justified by a syntactic-semantic argument (see Section 2.3 below).

\subsection{Syntactic-semantic evidence:}

Paraphrastic relationships are certainly the major source for identifying components in the underlying representations. However, it is rarely the case that for a sentence $\left(\mathrm{S}_{1}\right)$ containing some lexical item (V) there is a sentence $\left(\mathrm{S}_{2}\right)$ containing items (say, $\mathrm{X}_{1}$ and $\mathrm{X}_{2}$ ) which are potential factors of $\mathrm{V}$ and which is a paraphrase of $S_{1}$ i.e. , the composite item(say, $X_{1}\left(X_{2}()\right)$, (see section 4 for notations)) is rarely synonymous with $\mathrm{V}$. In other words, $\mathrm{X}_{1}\left(\mathrm{X}_{2}()\right)$ is not a definition of $\mathrm{V}$. A fruitful approach is to look for only 'incomplete definitions' (Miller, 1972) i.e., V implies $\mathrm{X}_{1}\left(\mathrm{X}_{2}(\mathrm{)})\right.$ but not necessarily vice versa. The definition of $\mathrm{V}$ in terms of $\mathrm{X}_{1}\left(\mathrm{X}_{2}()\right)$ is generally broader because $\mathrm{V}$ may have many other components narrowing its meaning. Miller (1972) has made extensive use of incomplete definitions in his analysis of the verbs of motion (see also Sections 2.8 and 3.4).

Arguments based on paraphrases and incomplete definitions combined with some syntactic evidence (to be called syntactic-semantic arguments) are the ones most popular with the linguists for obvious reasons (see Sections 2.1 and 2.7). We want some syntactic evidence to go along with the factorization arrived at by using paraphrases and incomplete definitions not only because we are interested ultimately in mapping the semantic representations onto the syntactic representations but also because it provides some control over the kind of paraphrases and incomplete definitions to be allowed (e.g., for move, we may allow change location (Miller, 1972) but possibly 
not acquire acceleration; for see, perceive by sight, may be allowed but not receives visual stimulus from, etc.). In our analysis of the verbs of seeing in Section 5, as far as possible, we will be looking for syntactic-semantic arguments in support of our factorizations.

A particularly strong syntactic-semantic argument (not always easy to find) runs as follows. A factorization of a lexical item (V), into a composite item (say X1(X2( ))) which is first suggested by a paraphrase or an incomplete definition is then justified as follows: We try to find a transformational rule (out of the bag of already well-established rules) which, in general, would apply only to sentences whose representation contains $\mathrm{X} 1(\mathrm{X} 2(\mathrm{)})$ and would also apply to sentences containing $\mathrm{V}$. If there is such a rule then this would require that sentences containing $\mathrm{V}$ should be given a representation containing X1(X2 (

)) which reflects the meaning of such sentences. Otherwise, two such rules would be necessary, one for sentences whose representation contains X1(X2( )) and one for sentences containing V (Lakoff, 1971). This is the kind of argument used by Postal (1970) in representing remind (in one of its senses) as perceive(x, similar(y, z)) (see also Section 3.3).

\subsection{Possible lexical items:}

Given a factorization and its representation according to a certain scheme (e.g. phrase structure trees, dependency trees, operator operand representation, etc.) we need some rule(s) for determining how two or more components can be 'merged'. We will call such rules 'predicate merging rules'. The merged components can then be replaced by a lexical item (lexical insertion), if possible. In the phrase structure formulation we have the predicate raising rule of McCawley. In the dependency formulation as well as in the operator-operand representation an analogous rule can be formulated. Fillmore (197I) and Anderson (1971) using dependency representation adopt a rule (not precisely formulated) which seems to be more powerful than the predicate raising rule. They call it 'conflation rule'. Given one of these predicate merging rules, if we can show that the nature of this rule is such that it will automatically prevent merging of components for which there cannot be possible lexical items and the merging permitted by the rule are the only possibilities for lexical insertion, then it may be possible to explain lexical gaps by classifying them as accidental or systematic. An accidental gap corresponds to the case when a composite predicate whose composition is permitted by the merging rules but for which there is no corresponding lexical item. A systematic gap, on the other hand, corresponds to the case of a composite predicate whose composition is not permitted by the merging rules. Thus, given a factorization and some predicate merging rule(s), the factorization can be justified by our ability to explain lexical gaps in a particular semantic domain. We should note however that an argument in favor of a particular predicate merging rule is not an argument supporting a particular factorization but rather it is an argument in favor of factorization itself and its particular representation i.e. in favor of a particular derivational system of formatives.

Sometimes a rather roundabout argument is given for justifying a particular factorization as follows: First, a factorization is justified in terms of some ad-hoc rule and then it is shown that this ad-hoc rule can be gotten rid of by adopting a predicate merging rule which is needed anyway (e.g. in the 'do' analysis of Ross (1971) the do deletion rule can be dispensed with; see Section 3.2. 
Let us examine the predicate raising rule. It allows one to move an embedded predicate and adjoin it to the left of the higher predicate in which it was previously embedded. Thus

$(2.4 .1)$

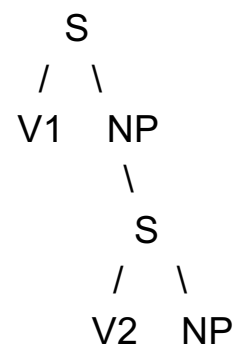

becomes

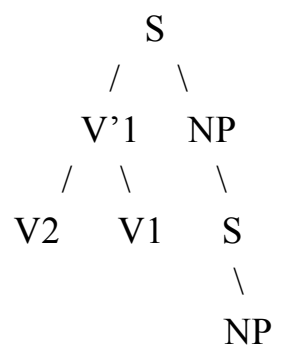

If V1 and V2 are called 'adjacent' predicates, then the rule says, roughly that only adjacent predicates can be merged. Hence, for example,

$(2.4 .3)$

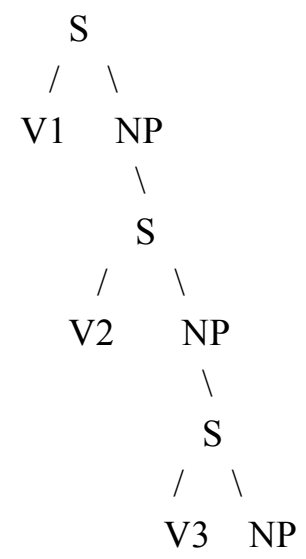

will not become 
$(2.4 .4)$

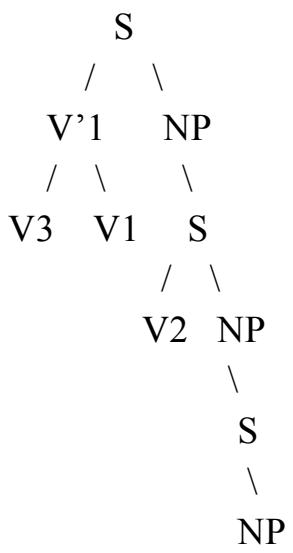

We can generalize this rule to two adjacent predicates on the same level. This generalization will then be the analog of the conflation rule described later. Let V2 and V3 be two predicates 'adjacent' to V1 on the same level, i.e., we have, for example,

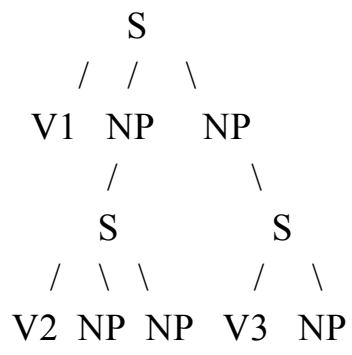

We can then merge V1, V2, and V3 as follows:

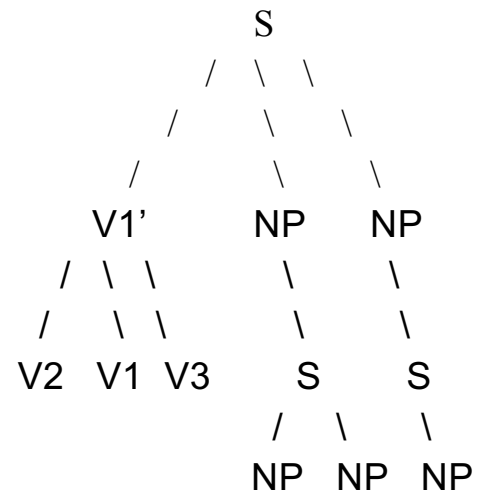


i.e. V2 is adjoined to the left of V1 and V3 to the right. In the dependency and also in the operatoroperand) representation, (2.4.7) below which is the analog of (2.4.5).

(2.4.7)

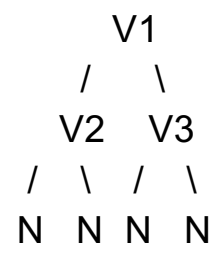

becomes by conflation (Filmore, 1971)

$(2.4 .8)$

$$
\begin{array}{cc}
\mathrm{V} 2 & -\mathrm{V} 1-\mathrm{V} 3 \\
\mathrm{I} & \mathrm{I} \\
\mathrm{N} & \mathrm{N}
\end{array}
$$

Thus (following Fillmore, 1971)

(2.4.9) I hit the ball

\begin{tabular}{|c|c|}
\hline \multicolumn{2}{|c|}{ cause } \\
\hline 1 & 1 \\
\hline hit & move \\
\hline 11 & 1 \\
\hline ball & b \\
\hline
\end{tabular}

which has an underlying representation

$(2.4 .10)$

corresponding roughly to

(2.4.11) My hitting the ball caused it to move (go over)

will become by conflation (i.e., (2.4.10) will become) 
$(2.4 .12)$

$$
\begin{gathered}
\text { hit-cause-move } \\
/ \quad 1 \\
\text { I ball }
\end{gathered}
$$

Replacing 'hit-cause-move' by the lexical item 'hit' we get (2.4.9). Similarly, we can conflate (2.4.13) to (2.4.14)

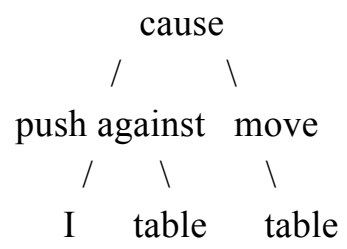

$(2.4 .14)$

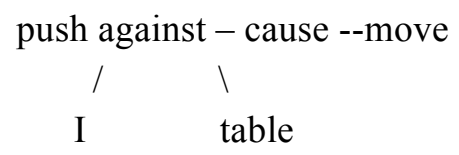

and replacing 'push-against-cause-move' by the lexical item 'push' we have

(2.4.15) I pushed the table

(2.4.13) explains why we have

(2.4.16) I pushed the table into the corner

but not

*(2.4.17) I leaned the table into the corner

i.e., the conflated item lean-against-cause-move is not replaced by a lexical item, thus, possibly, indicating an accidental lexical gap (Fillmore, 1971).

Harris (1970) who also adopts the operator-operand notation has a rule which places the operator in the second position i.e., after its first argument (cf. subject raising rule in the phrase structure transformational grammar). Thus given $X\left(Y_{1}, Y_{2}, \ldots Y_{k}\right)$ where $X$ is the operator and $Y_{1}, Y_{2} \ldots Y_{k}$ are the arguments, this rule produces $\mathrm{Y}_{1} \mathrm{XY}_{2} \mathrm{Y}_{3} \ldots \mathrm{Y}_{\mathrm{k}}$. He also allows rules for replacing certain discontiguous composite predicates by a single predicate. These two rules essentially accomplish the same effect as the conflation rule. Thus, for example, (using (2.4.10)), 
cause (hit (I, ball), move (ball))

will become

hit (I, ball) cause move (ball)

and then the discontiguous composite predicate 'hit-cause-move' can be replaced by a single predicate 'hit', leading to 'hit(I, ball)'. By applying once again the rule which places the operator in the second position we get 'I hit the ball'. Note that such a rule is needed anyway in order to get 'John ate the bread' from 'eat (John, bread)'. Harris seems to consider this rule as well as the rules for replacing the composite predicates (contiguous as well as discontiguous) by single predicates as extensions of morphophonemics, perhaps, reflecting his view on the abstractness of the basic predicates (see also Section 2.9).

\subsection{Redundancy:}

Given $S_{1}$, if $S_{2}$ is a paraphrase of $S_{1}$ and $S_{2}$ is the same as $S_{1}$ except for some additional elements (excluding some grammatical constants) then these extra elements are redundant and provide an indication for factorization of some element of $S_{1}$ into two or more components. For example, let $S_{1}=\underline{\text { he }}$ climbed the ladder and $S_{2}=$ he climbed up the ladder; then we can say that climb in $S_{1}$ 'incorporates' up (Gruber, 1965) and hence represent climb possibly as up (go ( )). Similarly, pierce can be represented as through (go ( )) (Gruber, 1965).

This technique is limited because we cannot get at all the components by producing appropriate redundant paraphrases. There is also another limitation. Sometimes, the putative redundant paraphrase is clearly unacceptable e.g., he walked $\rightarrow$ *he walked on foot (He travelled on foot is better). This suggests that walk might be represented as on foot (travel ( )). ) (Miller, 1971, Anderson, 1971).

\subsection{Regularization of predicates:}

One way predicates are classified is by the number of arguments required i.e., unary predicates, binary predicates, etc. Unary and binary predicates are certainly needed. Sometimes, a predicate requiring more than two arguments, in particular, a ternary predicate can be represented as a pair of binary predicates where one predicate is embedded in the ether. Thus give (John, boy, book) (John gave the boy a book), can be represented as cause (John, have (boy, book)) (John caused the boy to have a book) i.e., by the two predicates cause and have where have is embedded under cause. The possibility of reducing a ternary predicate (give, in this case) to two binary predicates eliminating a ternary predicate can be considered in itself as a justification (not the only one, to be sure) for a factorization(give $(x, y, z): \underline{\text { cause }}(\mathrm{x}, \underline{\operatorname{have}}(\mathrm{y}, \mathrm{z}))$ ) (Bierwisch, 1971, Harris, 1968). Some other examples of such regularizations are (Harris, 1968):

$\underline{\text { remove }}(\mathrm{x}, \mathrm{y}, \mathrm{z})$ (he removed the page from the book) : $\underline{\text { cause }}(\mathrm{x}, \underline{\text { lack}},(\mathrm{z}, \mathrm{y})$ (he caused the book to lack the page), attribute $(x, y, z)$ (he attributed the plan to her): claim (x, make ( $z, y)$ (he claimed that she made the plan), etc. 
It is not claimed here that all predicates requiring more than two arguments can be regularized in this way. There are some clear counterexamples such as between. (Bierwisch(1971) suggests the possibility of representing between as between $(x, y)$ where the second argument, $\mathrm{y}$, is a set of more than two objects.)

\subsection{Semantic evidence:}

Thus far we have considered only the semantic relationships of paraphrase and incomplete definition. We could, of course, consider other semantic relationships such as presupposition, semantic deviances of various kinds, contradictions, etc. A purely semantically based representation would indeed use such semantic relationships and many others. The main objective here is to provide suitable logical forms so that correct entailments will be deductible. No syntactic justification need be given and in fact it is not necessary. This is so because although actual sentences of the language may have been used informally to suggest some components and their possible organization, there is no obligation to provide machinery to map the logical forms onto actual sentences. The adequacy of such a representation could then be justified by appeal to actual sentences and their interpretation by subjects and there is no claim here that these representations are the underlying representations from which the actual sentences would be derived by some transformational rules familiar in linguistics.

The linguist's preoccupation with a syntactic (see Section 2.2) or a syntactic-semantic (see Section 2.3) arguments is fairly easy to understand. In addition to providing adequate semantic representations we must also describe the machinery for converting these semantic representations into actual sentences. This is also the reason for the assumption that the same sort of formal objects (e.g. trees) are used for both the syntactic and semantic representations (see Section 2.1).

Purely semantically based representations, therefore, need not be restricted to formal objects such as trees. They could be more complex objects. However, if one examines the representations which have been justified by purely semantic criteria one finds that this freedom of representation is hardly exploited at all. One reason for this could be the desire (and not a methodological obligation) to make these representations as suitable inputs to linguistic transformations. All this is a reflection of the fact that for natural languages there is no sharp line between syntax and semantics as is the case for formal or artificial languages.

Sometimes, for the components based on syntactic or syntactic-semantic arguments, we can find

correlates among the components set up on purely semantic considerations. This can be regarded as added support for the factorization (e.g., the do predicate for action verbs (Ross, 1971) and the intentionality predicate of Davidson (1970), see Section 3.2).

\subsection{Psychological evidence:}

Using incomplete definitions Miller (1972 a, b) has made an analysis of the verbs of motion. Incomplete definitions (see section 2.3) allow us to isolate the shared components of meaning of a set of lexical items i.e., the components with respect to which the items are similar in meaning without being 
necessarily identical in meaning. Miller depends on his method of incomplete definitions because it provides him with a characterization of judgments of similarity in meaning which appear to be confirmed by the results of his sorting experiments. Judges are asked to sort a set of words belonging to a particular semantic domain (e.g. motion verbs) into an unspecified number of piles. The data of such experiments is processed by some well-known techniques leading to "a kind of composite sorting into word clusters that reflect the commonest bases of semantic classification that the judges have used". Thus the components arrived at by using incomplete definitions are provided some psychological validity. Since the incomplete definitions are semantic definitions we can call this kind of argument semantic with psychological

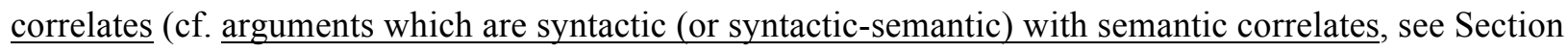
2.7).

2.9 Abstractness of the components:

So far we have not said anything about whether or not the components in the representation for a lexical item are themselves lexical items (or are to be lexically realized). On the one hand, we have used lexical items to represent the components and on the other we have called them predicates i.e., semantic verbs, thus suggesting that these components need not necessarily correspond to any lexical items in the language. There are a number of positions we can take concerning the lexical realizability of the components (Zwicky, 1971).

1. A component need not be lexically realized, thus allowing the possibility that none of the components are lexically realized.

2. A component must be lexically realized in some natural language.

3. Most components are lexically realized in the given language under consideration.

4. All components are lexically realized in the language under consideration.

The last position (cf. semantic postulates of Carnap) is the strongest one. It would be unnecessarily restrictive to hold this position. At the least we want to allow the kind of abstraction introduced when we set up an arbitrary element which is realized as one or another lexical item in the appropriate environments which are mutually exclusive (e.g., occur/do --> do $)$ in the context of a direct object; see Section 3.1 and 3.2). Also, since we are using incomplete definitions, our components are always somewhat abstract because if $\mathrm{Y}$ is a lexical realization of a component $\mathrm{X}$ then $\mathrm{X}$ is an incomplete definition of $\mathrm{Y}$ and there need not be (and, in general, will not be) a lexical item $\mathrm{Z}$ such that $\mathrm{X}$ is a complete definition of $\mathrm{Z}$. Confusion arises because we use $\mathrm{Y}$ itself as the name of this component i.e., we use the same expression for $\mathrm{X}$ and $\mathrm{Y}$. When we use a lexical item, say, $\mathrm{Y}$, to represent also a component in a representation of some lexical item, what we are asserting is that $\mathrm{Y}$ used as a component in some lexical item, what we are asserting is that $\mathrm{Y}$ used as a component in some representation is only an incomplete definition of the lexical item $Y$. This dual usage of $Y$ is not just a mnemonic device. It is a reflection of our desire to have the components, although abstract, 'fairly easily' lexically realizable. The troublesome part of all this is that we cannot state just how much incompleteness we would permit in our definitions and still adopt this double usage. Underlining, capitalizing, using bold face type, etc. are only notational devices to remind us of this problem but merely adopting these devices will not help us ignore 
the problem. This is what we mean by statements such as strike (or STRIKE) is not the same as 'strike', etc.

Although position 3 appears to be weaker than position 4, there is really no essential difference between them. Position 2 is quite attractive; however, it is hard to see (at least at present) how it can be usefully adopted in practice. Analyses of different and sufficiently large semantic domains is only beginning (excluding of course the well-known domains of kinship terms and color terms). We have as yet very little information about how general the components are (i.e., whether or not they occur in many different semantic domains) and how the representations in one domain carry over to some other semantic domains. Hence setting up components on the basis of their lexical realization in some language seems to be not a very useful procedure to follow at this time.

Position 1 would be justified if our aim is to set up representations such that these (and therefore, the components used in these representations) need only be justified in terms of their logical adequacy as the mathematical logicians do. But there is no reason to suppose that these components would be linguistically natural (e.g., not both - and - (i.e., Scheffer's stroke) is not lexically realized in any language (Zwicky, 1971); some other examples are Goodman's predicate 'grue', Prior's connective 'tonk', etc.) If a component is not lexically realizable in any language then representations using such components are not going to be very useful in the study of natural languages. They may be useful, however, in the descriptions of artificial languages.

It is interesting to note here an observation of Zwicky (1971) that in the semantic descriptions which have appeared so far, no components have been proposed which appear to be incapable of lexical realization.

For our present purpose we will adopt the following position: We would like the components to be relatively easily lexically realizable. This has the consequence that our semantic representations very often have a fairly immediate surface realization which may be however, quite unwieldy and marginal. How much abstractness we should allow will, perhaps, become clear when we know more about the kinds of substantial and formal universals which should be involved in our analyses of various semantic domains.

\section{Some examples of factorization:}

3.1. Nonstative verbs (occur analysis): It has been suggested that occur should be one of the components in the underlying representation of a nonstative verb (Lee, 1969, Ross, 1971). There is an agentivenonagentive ambiguity in

(3.1.1.) John collapsed.

The proposed underlying representations of (3.1.1) are

(3.1.2) occur (John, collapse (John))

(3.1.3) occur (collapse (John))

The agentive reading is obtained from (3.1.2) by subject formation and deletion of occur. The nonagentive reading is obtained by subject raising followed by subject formation and deletion of occur, i.e., (3.1.4) from (3.1.3) and (3.1.5) from (3.1.4). 
(3.1.4) occur (John, collapse (John))

(3.1.5) John collapsed.

Some of the arguments justifying the introduction of occur in the underlying representation of (3.1.1) are as follows (Lee, 1969).

1. For begin we also have the agentive-nonagentive distinction.

(3.1.6) John began to work.

(3.1.7) The faucet's dripping began.

(3.1.8) The faucet began to drip.

(3.1.6) is only agentive. (3.1.8) is nonagentive and (3.1.7) is a paraphrase of it. This can be explained by providing the following representations for (3.1.6) and (3.1.17) respectively.

(3.1.9) begin (John, work (John)

(3.1.10) begin (drip (faucet))

From (3.1.10) by subject raising and subject formation we obtain (3.1.8). Note that (3.1.7) corresponds to (3.1.10). The reason we are able to propose such an analysis is that we have a lower sentence available for

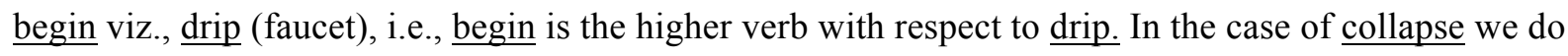
not have a lower sentence, i.e., we do not have a higher verb; so we invent occur. It is not a mere coincidence that we also have a lexical item occur (in the sense of 'happen') (see Section 2.9).

2. Analogous to (3.1.7) we now have

(3.1.11) John's collapsing occurred.

which corresponds to (3.1.3)

3. (3.13) also explains the it in

(3.1.12) John collapsed and I am sorry that it occurred.

4. Harris (1965) uses the occur predicate to explain the ambiguity in

(3.1.13) John may collapse.

Since we have two components occur and collapse, we may let may operate on one or the other component. Thus if may operates on collapse then from (3.1.2) we get (in the same way as we got (3.1.5))

(3.1.13) John may collapse.

On the other hand, if may operates on occur in (3.1.3) then we obtain (analogous to (3.1.11))

(3.1.14) John's collapsing may occur. 
From (3.1.14) we once again obtain (3.1.13) in much the same way as we obtained John collapsed from John's collapsing occurred.

5. Note that occur will not take a stative verb as one of its arguments.

* (3.1.15) John's being tall occurred.

So far, we have used here syntactic (Section 2.2) as well as syntactic-semantic (section 2.3) arguments.

3.2 Nonstative verbs (action verbs, 'do' analysis): In much the same spirit as the 'occur' analysis in Section 3.1, Ross (1971) has proposed do as one of the components in the underlying representation of an action verb.

The relationship of action verbs and do is clear from the fact that do (with animate subject) requires an abstract NP object which is an action nominalization.

(3.2.1) John did a study of earthquakes.

*(3.2.2) John did a knowledge of karate.

(3.2.1) can be derived from

(3.2.3) John studied earthquakes.

by some rule which inserts $\underline{\text { do }}$ in (3.2.3). However, there are several reasons for incorporating do in the underlying representation itself and then getting rid of it by some rule which deletes do (a rule rather similar to the rule for deleting occur in Section 3.1). It facilitates the derivation of (3.2.4) from (3.2.5) and (3.2.6) from (3.2.7) (Ross, 1971).

(3.2.4) Driving in the night I have always hated to do.

(3.2.5) I have always hated to do [driving in the night].

(3.2.6) Solving crossword puzzles is impossible to do.

(3.2.7) It is impossible to do [solving crossword puzzles].

Since we now have the rule for deleting do we can also obtain from (3.2.5) and (3.2.7) the following.

(3.2.8) I have always hated to drive in the night.

(3.2.9) It is impossible to solve crossword puzzles

Hence, it is proposed that the underlying representation of (3.2.1) should be 
(3.2.10) do (study (John, earthquakes))

By subject raising we get (3.2.11) and then by subject formation and do deletion we obtain (3.2.12).

(3.2.11) do (John, study (John, earthquakes))

(3.2.12) John studied earthquakes.

Alternatively, we can dispense with the do deletion rule by using a predicate merging rule (predicate raising or conflation rule, see Section 2.4). Thus from (3.2.10) we will obtain

(3.2.13) do-study (John, earthquakes)

Then a suitable lexical insertion rule will introduce study for do-study. Since the need for a predicate merging rule can be independently justified, if we can explain the derivation of (3.2.12) from do deletion rule which we just introduced for this purpose, then we have an added justification for the claim that do is a component in the underlying representation of an action verb (see Section 2.3).

Thus far we have used arguments which are either syntactic or syntactic-semantic (see Sections 2.2 and 2.3).

Ross gives yet another justification for the do analysis by suggesting that the do in the underlying representation of an action verb has a semantic correlate namely, the two-place action predicate intentional relating an agent and an event which Davidson (1970) has introduced in his analysis of action sentences. This analysis is purely semantic (see Section 2.7) i.e., based entirely on the suitability of logical forms for deducing correct entailments of action sentences, for being able to refer to action as a singular term, etc.

Finally we can combine the results of Sections 3.1 and 3.2 as follows. Do has the same restrictions with respect to its object complements (viz., it is an action nominalization) as occur has with respect to its subject complements. In both cases the main verb of the complement is nonstative (Lee, 1969). Hence, we can set up a predicate occur/do which is realized as occur in the context of a zero object and as do in the context of a direct object (see Section 2.9).

3.3 Remind: Postal (1970) has proposed that 'remind' (in one of its senses) should have the components perceive and similar in its underlying representation. In particular, the proposed incomplete definition of remind is

\section{(3.3.1) perceive $(x, \underline{\operatorname{similar}}(\mathrm{y}, \mathrm{z}))$}

From (3.3.1) by suitable transformations (from the set of already established ones) e.g., subject raising, psych-movement, and predicate raising, we obtain 
(3.3.2) y reminds $x$ of $z$.

It is possible to give a stronger justification by showing that there is a rule (viz., deletion of subjects in sentences like to shave oneself is to torture oneself) which is applicable when the clause where the deletion takes place is a complement of a verb of saying, thinking, perceiving, etc. This rule also applies to remind sentences. If remind is represented as (3.3.1) then this fact follows automatically because (3.3.1) contains perceive. If remind is not represented as (3.3.1) we will need two such rules, one for the sentences containing perceive etc. and one for the sentences containing remind. (For details of this argument and some other arguments, see Postal (1970) and Lakoff (1971).)

These arguments also are either syntactic or syntactic-semantic.

3.4 Motion verbs: Miller (1972a) has made a semantic analysis of a large number of motion verbs in English (e.g., move, travel, arrive, depart, walk, run, ride, etc.). His main motivation is to provide a framework for the study of the organization of lexical memory. The components are set up by using incomplete definitions. Since these are semantic relationships we must classify his arguments as semantic. However, they must be contrasted with the purely semantic arguments (Section 2.7) because only one type of semantic relationship is exploited in his analysis (viz., the incomplete definition) whereas a purely semantic argument is not necessarily restricted to only this relationship.

The only major syntactic consideration involved in his analysis is that all the items are of the same syntactic category (verbs). This is done primarily to keep some control over the context for comparison. Apparently, there is some psychological evidence for justifying this restriction.

The main components isolated are change, location, cause, allow, medium, instrument, etc. This analysis is then further justified by providing some psychological validity as described in Section 2.8. It is this kind of justification that forms the basis for the claim that such analyses are relevant to the study of lexical memory.

In summary, the arguments used are semantic (limited to only one type of relationship) with psychological correlates, in contrast to the analyses in Sections 3.1,3.2, and 3.3.

\subsection{Miscellaneous:}

1. A number of factorizations of individual verbs have been proposed. Some of which are:

give: cause $(\mathrm{x}, \underline{\text { have }}(\mathrm{y}, \mathrm{z})$ ) (syntactic-semantic argument plus the possibility of predicates with at most two arguments, see Section 2.6)

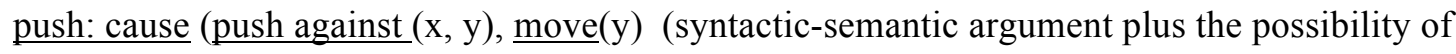


explaining some lexical gaps, see Section 2.)

$\underline{\text { lift: }} \quad \underline{\text { cause }}(\mathrm{x}, \underline{\mathrm{up}}(\mathrm{go}(\mathrm{y}))) \quad$ (syntactic-semantic argument)

etc.

2. Fillmore (1971) has made an analysis of some verbs of judging (e.g., accuse, criticize, scold, blame, excuse, etc.). The arguments are semantic and the semantic relationship of presupposition has been exploited extensively.

4. Notations and conventions:

4.1 Variables: $\mathrm{x}, \mathrm{y}, \mathrm{z}, \ldots$. These will generally range over concrete nouns and proper names.

$\underline{\mathrm{P}}, \underline{\mathrm{Q}}, \underline{\mathrm{R}}, \ldots$ Predicate variables.

4.2. Predicates: Predicates will be either unary or binary (a few ternary predicates will be needed). The arguments of a predicate may be variables $x, y, z \ldots$ or $\underline{P}, \underline{Q}, \underline{R}, \ldots$ the predicate variables. A predicate whose argument(s) can be another predicate is sometimes called an operator. We will often refer to predicates also as operators.

Examples:

$\underline{\mathrm{P}}(\mathrm{x}): \underline{\operatorname{run}}(\mathrm{John}):$ John ran.

$\underline{\mathrm{P}}(\mathrm{x}, \mathrm{y})$ : eat $(\mathrm{John}$, bread $):$ John ate bread.

$\underline{\mathrm{P}}(\mathrm{x}, \underline{\mathrm{Q}}()): \underline{\text { want }}(\mathrm{I}, \underline{\operatorname{run}}(\mathrm{John})):$ I want John to run.

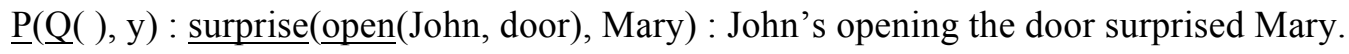

$\underline{\mathrm{P}}(\underline{\mathrm{Q}}()): \underline{\text { begin }}(\underline{\mathrm{run}}(\mathrm{John})):$ John began to run.

$\underline{\mathrm{P}}(\underline{\mathrm{Q}}(), \underline{\mathrm{R}}(\mathrm{)})$ : $\underline{\text { depend on }}$ (leave$($ Mary), arrive(John)) : Mary's leaving depends on John's arriving.

$\underline{\mathrm{P}}(\mathrm{x}, \mathrm{y}, \mathrm{z})$ : between(mirror, Marry, jewels) : The mirror is between Mary and the jewels.

We will not need for our present purpose predicates with no arguments such as $\underline{\text { rain }}()$ : it rained.

Unless otherwise stated, we will ignore tense, articles, and number.

We may want to specify for a predicate certain restrictions on its arguments (i.e., the range of the argument variables will be restricted).

Examples:

$\underline{\operatorname{run}}(\mathrm{x}): \mathrm{x}$ may not be inanimate.

$\underline{\operatorname{ask}}(\mathrm{x}, \underline{\mathrm{P}}(\mathrm{)})$ : $\mathrm{x}$ may not be nonhuman. $\underline{\mathrm{P}}$ cannot be a predicate such as want $(\mathrm{y}, \underline{\mathrm{Q}}(\mathrm{)})$ : * $\underline{\mathrm{I} \text { asked }}$

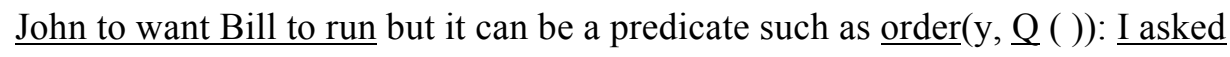
John to order Bill to run. 
4.3 'Suppressed' argument: An argument variable with a \# denotes a suppressed argument (x\#, y\#, z\#,..),. This allows us to interpret, for example, a binary predicate as a unary predicate by ignoring (or presupposing) the suppressed argument (Fillmore, 1968). If the suppressed argument has some restrictions on it then it is understood that it is specifiable (recoverable) only up to these restrictions. This convention of a suppressed argument is the same that of Fillmore's except that he allows only the variables to be suppressed whereas we allow here the suppression of predicate variables also. If an argument is suppressed then the arguments of that argument, etc. are also all understood to be suppressed.

5. Verbs of seeing:

\subsection{Introduction:}

An analysis of some seeing verbs is presented in the following sections. There are about 60 verbs in the list in Section 5.3 satisfying more or less the criteria in Sections 5.2. About 15 of these are clearly seeing verbs and are also core verbs in the sense that the representations for these are adequate to account for the remaining. Before a detailed list was made the expectation was that the number would be in the hundreds. Thus it was somewhat surprising to find that the number was not very large (hearing verbs are even fewer).

The analysis which is initially arrived at by using paraphrase relationships and incomplete definitions is justified by providing as much evidence as possible of the kind described in Sections 2.2 2.7. The analysis is divided in 11 subsections. In each subsection an analysis of a key verb (or verbs) is presented and all related verbs are listed with appropriate comments. A list of predicates used and a list of representations is given in Sections 5.5.1 and 5.5.2 respectively. A quick look at these two lists and the list of verbs in Section 5.3 will give the reader some idea of the analysis that is attempted here.

Throughout Section 5.4 and in Sections 5.5.3 and 6 we carry out a comparison with the hearing verbs and other verbs of perception.

\subsection{Criteria for verbs of seeing:}

By verbs of seeing, we mean verbs which in one of their senses involve visual perception (see, look, appear, gaze, glance, view, blind, hide, display, expose, etc.) A list of such verbs is given in Section 5.3 (approximately 60). We are concerned here with verbs which are single lexical items (with a few exceptions such as look at and look for) and not with frozen expressions which may serve as seeing verbs (e.g. keep an eye on). Many of these verbs have both a visual and a nonvisual sense. Unless otherwise stated, it is only the visual sense that we will be concerned with.

A seeing verb involves visual perception in many different ways: 1 . The subject of the verb sees something or the object of the verb becomes visible (e.g. see: $\underline{X \text { saw Y }}$ ). 2. The subject directs sight in

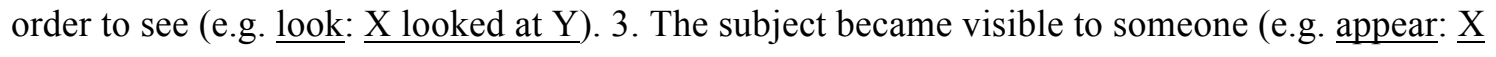
appeared). 4. The basic predicates of see, look, and appear are 'modulated' (modified) by other predicates 
such as cause, $\underline{\text { not }}, \underline{\text { momentary, }} \underline{\text { continual, }}$ etc. yielding a variety of seeing verbs such as hide, $\underline{\text { expose}}$, glance, gaze, etc.

There are a number of verbs which pertain to modes of emitting or reflecting light from an object and do not have any additional sense of either increasing or decreasing the visibility (e.g. glimmer, glisten, shine, etc., see Section 5.3.2). We do not consider these as seeing verbs. Verbs such as dazzle,

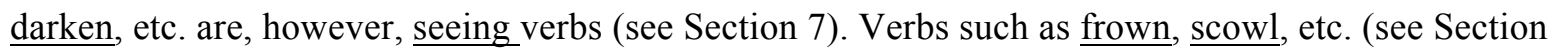
5.3.3) involve movement of eyes, eyebrows, or face but not visual perception. Clearly, these are not seeing verbs.

When a verb optionally involves visual perception it is difficult to give a very sharp criterion for including or excluding it from our list. We include such a verb when it can be essentially represented by $\underline{\text { see, }}$ look , or appear together with one or more additional predicates (such as cause, not, momentary, continual, etc.) which appear in many other semantic domains. If these additional predicates pertain to some specific semantic domain (other than that of seeing verbs) such as, for example, communication verbs, then we will not consider such a verb as a seeing verb (e.g., waive, signal, point out, etc.). Verbs such as meet, be at, go to, etc. are also not seeing verbs; however, we will briefly discuss these in Section 1.5 because they are replaceable by see in certain contexts. Verbs such as $\underline{\text { ind }}, \underline{\text { detect, }}$, are not seeing verbs; however, they are used in the representation of some seeing verbs (see Section 5.3.1).

Finally, visualize is not a seeing verb!

5.3 A list of verbs of seeing:

$\begin{array}{lll}\text { appear } & \text { flash } & \text { scrutinize } \\ \text { behold } & \text { flaunt } & \text { secrete } \\ \text { blind } & \text { gaze } & \text { screen } \\ \text { blur } & \text { glance } & \text { see } \\ \text { conceal } & \text { glare } & \text { search } \\ \text { cover } & \text { glimpse } & \text { seek } \\ \text { darken } & \text { hide } & \text { show } \\ \text { descry } & \text { inspect } & \text { sight } \\ \text { disclose } & \text { look } & \text { spot } \\ \text { dazzle } & \text { mask } & \text { stare } \\ \text { display } & \text { notice } & \text { surface } \\ \text { disappear } & \text { obscure } & \text { survey }\end{array}$




$\begin{array}{llc}\text { discern } & \text { observe } & \text { uncover } \\ \text { emerge } & \text { overlook } & \text { unmask } \\ \text { espy } & \text { peek } & \text { vanish } \\ \text { examine } & \text { peep } & \text { view } \\ \text { expose } & \text { peer } & \text { watch } \\ \text { exhibit } & \text { reappear } & \text { witness } \\ \text { eye } & \text { regard } & \\ \text { fade } & \text { resemble } & \\ \text { fade-in } & \text { reveal } & \\ \text { fade-out } & \text { scan } & \end{array}$

The following are not seeing verbs:

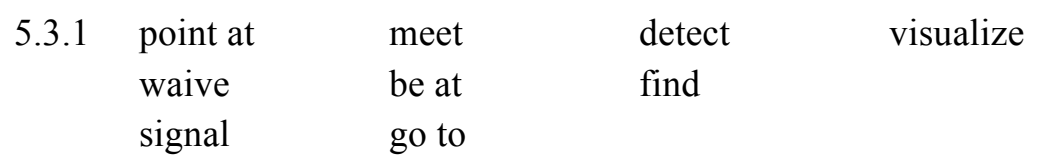

$\begin{array}{lll}\text { 5.3.2 } & \text { brighten } & \text { shine } \\ \text { sparkle } & \text { glow } \\ \text { glitter } & \text { light (brighten) } \\ \text { glisten } & \text { twinkle } \\ \text { shimmer } & \text { illuminate } \\ \text { gleam } & \end{array}$

$\begin{array}{lll}\text { 5.3.3 } & \text { frown } & \text { wink } \\ & \text { scowl } & \text { blink } \\ & \text { glower }\end{array}$

5.4 Analysis of some verbs of seeing:

1. $\underline{\text { See }}$

There are two major subcategorizations of the verb 'see': intransitive and transitive. As a transitive verb it can take a nominal or sentential (nonpropositional or propositional) object. There are many subcases of each one of these subcategorizations and we will consider them one by one. In most cases, see will have 
both the visual as well as the nonvisual sense. Unless otherwise indicated we will always be concerned with the visual sense only.

1.1 see (v.t.). Direct object is a concrete noun (with a definite or indefinite article).

\section{(1.1.1) John saw a cat.}

We will define 'see' as follows

\section{(1.1.2) $\underline{\text { by sight }}($ perceive $(x, \underline{P}(s)))$}

The predicate (predicate variable) $\underline{P}$ has the sense of a classifier (identifier, or describer) e.g., $\underline{P}$ can be a noun such as cat, book, etc., a proper name such as $\underline{\text { John, }} \underline{\text { Mary, etc. s has the sense of something with }}$ some characteristics. Strictly speaking, $\mathrm{s}$ is a variable. However, we will never (as in (1.1.13)) substitute anything for s; hence, it can be considered more like a constant. Thus (1.1.1) has the representation

\section{(1.1.3) by sight (perceive (John, $\underline{\text { cat }}(\mathrm{s})))$}

i.e., (1.1.1) can be roughly paraphrased as

(1.1.4) John perceived by sight something which was (classified, or identified as) a cat, (or possibly as John perceived by sight that something was a cat).

One reason for setting up (1.1.2) is that it can be carried over to other cases of see as well as the other verbs of perception. (1.1.2) allows us to reduce all cases of see (v.t.) to the case requiring a sentential object; each case will differ only in the type of predicate allowed for $\underline{P}$. The need for isolating the component by sight is obvious if we wish to carryover (1.1.2) to other verbs of perception. Setting up the predicate $\underline{\mathrm{P}}$ (under perceive) also helps to account for such cases as

I heard John (at the door).

which would be represented as

by hearing(perceive $(\underline{\mathrm{I}}, \underline{\mathrm{John}})(\mathrm{s})))$

where $\mathrm{s}$ is something (or some sound).

We can give some justification for (1.1.2) (admittedly, not a very strong one) in terms of restrictive and nonrestrictive relative clauses. It is claimed that indefinite noun phrases support only restrictive relative clauses (Smith, 1964), but the situation is not so clear (Bach, 1968). In addition, even with a restrictive relative clause the verb seems to make a difference.

(1.1.5) I saw something which was a cat.

? (1.1.6) I threw something which was a ball. 
(1.1.5) can be a paraphrase of (1.1.1)

(1.1.6) is odd and it is also odd as a paraphrase of (1.1.8).

(1.1.8) I threw a ball.

Now consider (1.1.5) and (1.1.6) where the relative clause is nonrestictive i.e.,

(1.1.7) I saw something, which was a cat.

(1.1.8) I threw something, which was a ball.

Now, nonrestrictive relative clauses have the property that they can have a truth value vouched for by the speaker and independent of context in which they are inserted (Bach, 1968, attributed to Ross). This is certainly possible for (1.1.8). However, an interpretation of (1.1.7) where the truth value the speaker vouches for is independent of context (i.e. the context of his seeing something) is extremely odd indeed.

Thus it appears that we cannot have a nonrestrictive relative clause on something with see but can have such a clause with throw (an example of a nonperceptual verb) and that we can have a restrictive relative clause on something with see but only marginally with throw. This suggests that the predicate $\underline{\mathrm{P}}$ should be under perceive rather than something like

\section{(1.1.10) $\underline{\text { by sight }}($ perceive $(\mathrm{x}, \mathrm{s})) \& \underline{\mathrm{P}}(\mathrm{s})$}

The claim here is not that only perceptual verbs have the properties described above. There are some nonperceptual verbs (eat, drink, catch (?), etc.) which seem to have similar properties.

? I ate something which was spaghetti.

If we accept (1.1.2) as the representation of see then

(1.1.11) I saw something

would be represented as

(1.1.12) by sight (perceive $\left.\left(x, P^{\prime}\right)\right)$

where $\mathrm{P}$ ' denotes that $\mathrm{P}$ is 'suppressed'.

Our representation (1.1.2) reduces the direct object construction to a propositional object construction. It is interesting to note that Hintikka (1969) also treats the direct object construction as not irreducible. He treats perceptual concepts as intentional concepts or modal concepts in general (partly motivated by some problems raised by Anscombe (1965)). His analysis leads him to regard perceptual terms as expressing propositional attitudes. In particular, he reduces the direct object construction to the 'perceive that' 
construction (see (1.1.4)) and thus suggests a representation which is almost the same as (1.1.2) (see also Pitcher, 1971, p.82). His arguments are semantic (in the sense of Section 2.7). Thus our representation 1.1.2) which was arrived at by an essentially syntactic-semantic argument (see Section 2.3) now has a semantic correlate (cf. do analysis in Section 3.2).

(1.1.2) may also serve to represent look-like (or resemble)

(the table looks like a chair to me $\approx$ ?? I see the table as a chair)

(1.1.3) by sight (perceive (I, chair, (table)))

1.2 see (v.t.). Sentential object.

(1.2.1) John saw Mary crossing the street.

(1.2.2) John saw Mary cross the street.

(1.2.3) John saw that Mary was crossing the street.

(1.2.4) John saw that Mary crossed the street.

(1.2.5) I saw her home safely.

(1.2.6) I saw that she was home safely.

(1.2.7) I saw him get angry.

(1.2.8) I saw him angry.

(1.2.9) I saw him tired.

Now let

(1.2.10) by sight (perceive $(\mathrm{x}, \underline{\mathrm{Q}}(\mathrm{)}))$

be the representation for see (v.t.) where the predicate $\mathrm{Q}$ has the sense of an action, activity, act, or event (i.e., if Q( ) were to be a nominalization then it would be an action nominalization). Thus

(1.2.1) can be represented as

(1.2.11) by sight (perceive (John, cross $($ Mary, street) $))$

(1.2.2) can be similarly represented. In (1.2.2) we have a completed activity (or an event). Note that in (1.2.1) and (1.2.2) we do not have an action nominal but rather a predicate complement construction. There is a difference between (1.2.1) and (1.2.12) below

?(1.2.12) John saw Mary's crossing of the street.

which has an action nominal. (1.2.2) has the interpretation of

$\underline{\text { John saw Mary engaged in the activity of crossing the street }}$

(1.2.1) and (1.2.2 can be respectively paraphrased as 
(1.2.13) John saw Mary as she was crossing the street.

(1.2.14) John saw Mary as she crossed the street.

On the other hand (1.2.12) can be paraphrased as

(1.2.15) John saw the activity, namely, Mary's crossing of the street.

We will ignore this distinction between action nominal constructions and predicate nominal constructions i.e., we will be concerned with only the sense of an action, act, event, etc. and will ignore the additional semantic interpretation of the predicate complement constructions.

In (1.2.15) the word activity has been explicitly introduced. Since we must account for (1.2.15) and other similar sentences (Fraser, 1970):

(1.2.16) We saw the act, namely, their destroying of the building (We saw them destroy the building).

(1.2.17) We saw the event, namely, his taking of an oath (We saw him take an oath).

(1.2.18) We saw the process, namely, the jeweler's melting down the silver (We saw the jeweler melt down the silver).

Hence, instead of (1.2.10) we will choose the following representation.

(1.2.19) by sight (perceive $(x, \underline{\operatorname{act}}(\underline{Q}()))$

where act is a new predicate and has the sense of an activity, action, event, or process. Thus (1.2.1) can be represented as

(1.2.20) $\underline{\text { by sight }}(\underline{\text { perceive }}(\underline{\text { John }}, \underline{\operatorname{act}}(\underline{\operatorname{cross}}($ Mary, street $)))$

Now, (1.2.3) and (1.2.4) (in one of their readings) can also be represented by (1.2.10) or (1.2.19) (i.e., by (1.2.11) or (1.2.20). But (1.2.3) and (1.2.4) also have a factive reading. Perhaps, this reading comes out better if saw is replaced by noticed. The co-occurrence restrictions for action nominalizations (as well as for action nouns) are different from those for factive nominalizations. The shapes of the strings are also different in general (Fraser, 1970).

(1.2.21) John's riding of the bicycle startled them. (action)

(1.2.22) John's riding the bicycle bothered them. (factive)

For see, we have both the readings. The shapes of the nominalized strings are different. In one case (action) we have the predicate complement construction and in the other (factive) the 'that $\mathrm{S}$ ' construction. For strong nominalizations e.g., refusal (in contrast with refusing), destruction (in contrast with destroying), etc., the distinction between action and factive is not marked with a difference in string shapes. Hence we have 
(1.2.23) His refusal to attend the meeting startled us.

(1.2.24) His refusal to attend the meeting bothered us.

Thus (1.2.25) below is ambiguous.

(1.2.25) We saw the destruction of the city.

Hence, we should represent. (1.2.3), (1.2.4), and (1.2.25) in their factive readings by

(1.2.26) by sight (perceive $(x, \underline{\text { fact }}(\underline{Q}()))$

Thus for (1.2.25) we have

(1.2.27) by sight (perceive (we, fact (destroy $(y$, city)))

In (1.2.19) the predicate $\underline{Q}$ is under the predicate act and $\underline{Q}$ is restricted to an action predicate (e.g. $\underline{\text { cross }}$ ). But in (1.2.26) there is no such a restriction. Hence, we have

(1.2.28) I saw that John had a new a car.

(1.2.4) (and possibly (1.2.3) also) has an additional reading something as follows.

(1.2.29) I made sure visually that Mary crossed the street.

Since this reading is valid only for the factive nominalization, we can represent it as follows.

(1.2.30) by sight (make sure $(x, \underline{\text { fact }}(\underline{Q}()))$

(1.2.30) will also take care of (1.2.5) and (1.2.6).

We are now left with (1.2.7), (1.2.8), and (1.2.9). (1.2.7) easily fits (1.2.19):

(1.2.31) by sight (perceive (I, act (get (angry (he))))

(1.2.8) and (1.2.9) seem to be quite odd. In any case, since they can be paraphrased as

(1.2.32) He looked angry (to me).

(1.2.33) He looked tired (to me).

We will include them in our discussion of look.

\section{3 see (v.i.)}


(1.3.1) I see now.

(1.3.2) I can see now.

(1.3.3) It is possible for me to see now.

(1.3.4) I am able to see now.

(1.3.5) I can see through the fog.

(1.3.6) Do you see now?

(1.3.7) Can you see now?

(1.3.8) I can see the peak now.

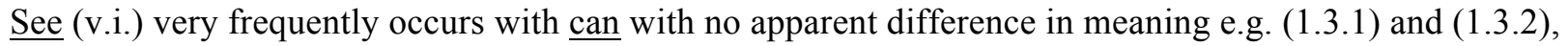
(1.3.6) and (1.3.7). This is true for other verbs of perception also (see for example, (Palmer, 1968; Vendler, 1968). Hence, we will represent see (v.i.) as follows.

(1.3.9) possible (by sight (perceive $(\mathrm{x}, \mathrm{P} * \mathrm{~s}))$ )

where * indicates that the second argument of perceive i.e. $\underline{P}$ is suppressed. According to our convention concerning a suppressed argument, we can only specify (or recover) the second argument up to $\underline{P}$ i.e., up to the type of the predicate we can substitute for $\underline{P}$ including whatever restrictions that may have been specified for the arguments of this predicate. We will restrict $\underline{P}$ to a predicate of the type allowed in (1.1.2), namely, a predicate with sense of a classifier or identifier. Further, the predicate 'possible' is to be taken in the sense of 'capable'.

Instead of (1.3.9), we could have chosen a representation in which we simply drop the second argument and let perceive have only one argument. But this requires us to set up a completely new representation for see (v.i). (1.3.9) has the advantage that it differs from (1.1.2) only in the fact that the second argument of perceive is 'suppressed'; and the convention of suppressed argument is useful elsewhere also.

The component possible in (1.3.9) is also helpful in accounting for (1.3.10) where see can appear with a direct object. (1.3.10) is a paraphrase of (1.3.8).

(1.3.10) It is possible for me to see the peak now.

The representation of (1.3.10) is the same as (1.3.9) except that $\underline{P}$ is now specified

Note that (1.3.10) is a paraphrase of

(1.3.11) The peak is visible to me now.

Hence, we can regard visible as a composite predicate. Thus (1.3.12) below is equivalent to (1.3.9).

(1.3.12) visible $\left(x, \underline{\mathrm{P}^{*}}(\mathrm{~s})\right)$

The representation for 
(1.3.13) The peak is visible now.

will be

(1.3.14) visible( $\left(\mathrm{x}^{*}, \underline{\mathrm{P}}(\mathrm{s})\right)$

where both the arguments are suppressed.

'Overlook' can also be represented by

(1.3.9) The window overlooks the garden.

The garden is visible from the window.

One can see the garden from the window.)

(For another sense of overlook, see Section 5.4 - 2.)

\subsection{Summary:}

We now have the following definitions for see.

(1.1.2) by sight (perceive $(\mathrm{x}, \underline{\mathrm{P}}(\mathrm{s})))$

(1.2.19) by sight (perceive $(x$, act $(\mathrm{Q}(\mathrm{)})))$

(1.2.26) by sight (perceive $(\mathrm{x}$, fact $(\mathrm{Q}(\mathrm{)})))$

(1.2.30) by sight (make sure $(\mathrm{x}$, fact $(\mathrm{Q}())))$

(1.3.9) possible (by sight (perceive $(\mathrm{x}, \underline{\mathrm{P}}(\mathrm{s})))$ )

These definitions can be easily carried over to other non-visual verbs of perception especially to verbs of hearing by suitably replacing the mode of perception component e.g. by replacing by sight by by hearing. There are some special and interesting problems concerning the verbs of hearing; but we will discuss these later.

1.5 There are still some uses of see which we have left out.

(1.5.1) I saw an error in the manuscript ( $\approx$ I found an error in the manuscript.).

(1.5.2) We saw poverty everywhere.

(1.5.3) I saw him in Philadelphia last month $(\approx$ I met him in Philadelphia last month.).

(1.5.4) I saw him to the airport ( $\approx$ I accompanied him to the airport.).

(1.5.5) I saw a movie yesterday ( $\approx$ I was at a movie yesterday.).

(1.5.1) sounds better with saw replaced by noticed. It can then be represented by (1.2.26). (1.5.2) can also be treated similarly. (1.5.3), (1.5.4), and (1.5.5) need not necessarily involve visual perception. Note also that in (1.5.5) we can introduce the auxiliary 'go' and optionally delete 'see'. 
(1.5.6) I went to see a movie yesterday.

(1.5.7) I went to a movie yesterday.

These can be handled by requiring that 'meet', 'accompany', be at (a movie), go to (a movie), etc. have 'see' as an optional component. (1.5.4) in the sense of make sure is already covered by (1.2.30).

2. $\underline{\text { Look }}$

$2.1 \underline{\text { look}}$. With a PN object, $\mathrm{P}=$ at, towards, $\underline{\text { into }}$, $\underline{\text { across}}$, etc.; but not for

(2.1.1) He looked at the tree.

(2.1.2) He looked towards the tree.

(2.1.3) He looked into the cave.

Look syntactically behaves like aim (head or direct) (Gruber, 1967).

2.1.4) He aimed (directed) his sight (gaze?) at the tree.

(2.1.5) He aimed his sight towards the tree.

(2.1.6) He aimed his sight into the cave.

The noun phrase after the preposition (e.g., the tree in (2.1.1)) specifies the location towards which the sight is directed but is itself not necessarily the object intended to be seen.

(2.1.7) I looked towards the sky (in order to see the plane) but didn't see it (the plane).

This suggests the following representation

(2.1.8) $\underline{\text { in order to }}(\underline{\text { by sight }}(\underline{\operatorname{aim}}(\mathrm{x}, \underline{\text { location }}(\mathrm{y}), \underline{\text { possible }}(\underline{\text { by sight }}($ perceive $(\mathrm{x}, \underline{\mathrm{P}}(\mathrm{s})))))$

The second argument of in order to is just the representation for see (v.i.) in (1.3.9). Note that the restrictions on $\underline{\mathrm{P}}$ in (2.1.8) are precisely the same as in (1.3.9). Thus this is an additional justification for the representation in (1.3.9).

The first argument of in order to could have been simply written as aim sight $(x, y)$ with suitable restrictions on $\mathrm{x}$ and $\mathrm{y}$. However, the location predicate is important enough in its own right and also it is needed in other semantic domains (e.g., verbs of motion (Miller, 1971a)). Hence, we will represent it explicitly. We also want to factor out sight (or by sight) out of 'aim sight' so that first we can factor by sight out of both the arguments of in order to, and secondly, we can investigate the possibility of using the same representation for other verbs of perception by making some obvious changes. Finally, we may replace in order to by causative (of intention) (or cause-intent). Verbs such as look at (or watch) designate purposive activities. ${ }^{1}$ They take manner adverbs such as carefully, efficiently, etc. Further, we cannot

\footnotetext{
${ }^{1}$ Ryle (1949) calls see, hear, etc. achievement verbs and look, listen, etc., activity or task verbs. This classification is not very useful to us mainly because (as Sibley (1955) correctly points out) 1 . His classification is arrived at by
} 
consent or refuse to look at (or watch) in contrast with see (Chisholm, 1957). Also try can operate on look at but not on see i.e., we have I tried to look at the plane but not I tried to see the plane. This justifies the cause-intent predicate. Hence, instead of (2.1.8) we will have

(2.1.9) cause-intent (by sight (aim $(x y$ lose $(y))$, possible (by sight (perceive $(x, \underline{P}(s)))))$

which is equivalent to (on account of (1.3.11))

(2.1.10) $\underline{\text { cause-intent }}(\underline{\text { by sight }}(\underline{\operatorname{aim}}(\mathrm{x}, \underline{\text { loc }}(\mathrm{y}))$, visible $(\mathrm{x}, \underline{\mathrm{P}}(\mathrm{s})))$

We could, of course, take cause-intent as a composite predicate cause (intent ( )). This latter representation has no advantage for us at present; hence we will not adopt it. Later on we will also introduce cause-result (see Section 4).

2.2 look. With adjectival or nominal complement.

(2.2.1) He looked tired (to me).

(2.2.2) He looked happy (to me).

(2.2.3) He looked angry (to me).

(2.2.4) He looked guilty (to me).

(2.2.5) He looked a gentleman,

(2.2.6) The stick looked bent.

(Look is distinguished from appear (and seem) because although appear can appear in (2.2.1) - (2.2.6), it can also appear in (Austin, 1962)

(2.2.7) It appeared to expand.

(2.2.8) He appeared to like her.

(2.2.9) It appears that they have all left.

(Look does not appear in these constructions.)

We can paraphrase (2.2.1) by

(2.2.10) He had a tired look (on his face, on him).

confusing look at and look for as well as look for and observe and 2. He is equating see with spot and thus essentially ignoring other senses of see (see also Section 5.4-9).

Incidentally, Sibley (1955) examines a number of seeing verbs and his paper is the only one I have come across which is not restricted to the obviously seeing verbs, see, look, and appear. The main objective of his paper, however, is to show the weakness of Ryle's classification and suggest some alternatives.

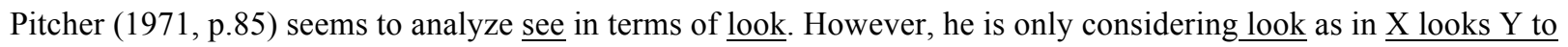
$\underline{Z}$ and indeed our representation $(1.1 .13)$ can also be interpreted as representing see in terms of look. 
(2.2.11) I saw a tired look on him (on his face).

(2.2.12) I saw him tired.

and similarly (2.2.2) - (2.2.4). For (2.3.5) we have

(2.2.13) He had a gentlemanly look (on him, about him, on his face).

(2.2.14) I saw a gentlemanly look (on him, on his face).

(2.2.15) I saw him gentlemanly.

and for (2.3.6)

(2.3.16) The stick had a bent look ( ? on it).

(2.3.17) I saw a bent look on the stick.

$(2.3,18)$ I saw the stick bent.

The adjectival or nominal complement describes a state (I saw him in a tired state). Hence, we may represent look as

2.2.19) by sight $($ perceive $(x, \underline{\operatorname{state}}(\underline{\mathrm{R}}(\mathrm{)})))$

where $\mathrm{g}$ is a predicate of state (e.g., angry) distinguished from the action predicate in (1.2.19), Thus (2.2.3) will be represented as follows.

(2.2.20) by sight (perceive (I, state (angry (he))))

2.3 Summary:

We now have the following definitions for look.

(2.1.9) cause-intent (by sight $(\underline{\operatorname{aim}}(0(\mathrm{y}))))$, possible (by sight (perceive $(\mathrm{x}, \underline{\mathrm{P}}(\mathrm{s})))))$

(2.1.19) by sight (perceive $(x, \underline{\text { state }}(\underline{\mathrm{R}}()))) \quad \underline{\mathrm{R}}$ : state predicate.

(2.2.19) easily carries over to nonvisual verbs of perception. In particular,

(2.3.1) by hearing (perceive $(x, \underline{\text { state }}(\underline{\mathrm{R}}())))$

will correspond to sound as in the bell sounded sharp. (2.1.9) does not carry over immediately. Consider

(2.3.2) $\underline{\text { cause-intent }}(\underline{\text { by hearing }}(\underline{\operatorname{aim}}(\mathrm{x}(\underline{\mathrm{loc}}(\mathrm{y}))))$, possible $(\underline{\text { by hearing }}($ perceive $(\mathrm{x}, \underline{\mathrm{P}}$ ' $(\mathrm{s}))))))$

The aural counterpart of look is listen but listen does not involve (explicitly) the directional component. The directional prepositions at, towards, into, across, etc. do not appear after listen just as they do after look. Thus (2.3.2) is not a correct representation for listen. 


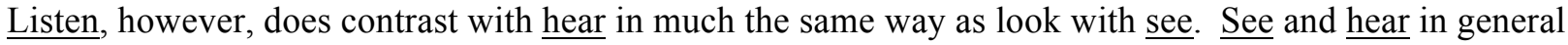
will not take progressive while look and listen will (Gruber, 1967).

(2.3.3) I was looking at the tree.

(2.3.4) I was seeing the tree.

(2.3.5) I was listening to a symphony.

(2.3.6) I was hearing a symphony.

Also see and hear are no agentive while look and listen are. Hence, the latter can take manner adverbs such as carefully, etc.

(2.3.7) I looked at the bird carefully.

(2.3.8) I saw the bird carefully.

(2.3.9) I listened to the symphony carefully.

(2.3.10) I heard the symphony carefully.

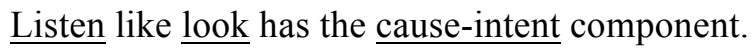

(2.3.11) I listened carefully but didn't hear any click.

$\underline{\text { Listen }}$ and look both involve directing attention.

(2.3.12) Look here (there, around)

(2.3.13) Listen to me

(2.3.14) Listen to the tape recorder

(2.3.15) Listen to the music

$(2,3.16)$ Listen here (there, around)

(2.3.16) again shows that directionality is not (explicityly) involved in listen. Hence, we can represent

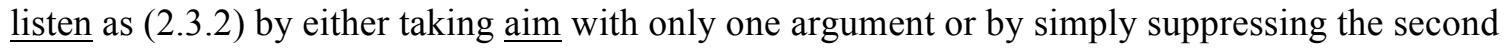
argument of aim. We will choose the latter alternative.

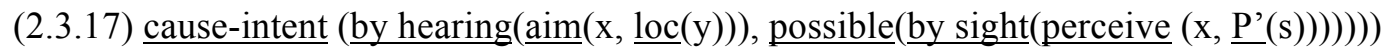

It would be interesting to see how the see-look and the hear-listen distinction as well the lack of directionality or location components for listen shows up in other languages. In some languages (e.g. Marathi) there are distinct lexical items that roughly correspond to see and look but the hear-listen distinction does not appear lexically and further the lexical items corresponding to hear or listen do not involve directionality or location. There are languages (e.g. Hindi) where the see-look distinction also disappears, although the lexical item corresponding to see or look retains the directionality or location component. (Is there a language where there is no see-look distinction and yet there is hear-listen distinction?) Dixon (1971) describes the nounmarkers in Dyirbal (an Australian aboriginal language) which specify the visibility-location of the referent of the noun. The three forms are: 
1. there and visible

2. here and visible

3. audible and not visible (with no locational component).

This distinction is for noun-markers and not for verb-markers, however.

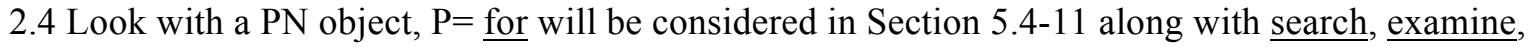

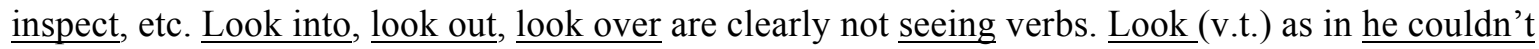
look us in the face is also not a seeing verb.

\section{Appear}

3.1 appear v.i.) (to come into sight). For appear with adjectival complements, see look (Section 2.2).

$(3,1.1)$ A ship appeared on the horizon.

(3.1.2) John appeared at the door.

(3.1.3) A ship began to be visible (to me) on the horizon.

(3.1.4) I began to see a ship on the horizon.

??(3.1.5) I saw a ship appear on the horizon.

??(3.1.6) I saw John appear at the door.

(3.1.1) and (3.1.3) are near paraphrases. (3.1.5) is awkward because of redundancy (i. e., appear already has 'see' as a component). (3.1.4) is not redundant and it is a paraphrase of (3.1.3) (with to me). Thus

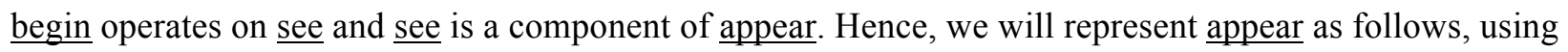
(13.9).

(3.1.7) $\underline{\text { begin }}\left(\right.$ possible $\left.\left(\underline{\text { by sight }}\left(\underline{\text { perceive }}\left(\mathrm{x}, \underline{\mathrm{P}^{\prime}}(\mathrm{s})\right)\right)\right)\right)$

Thus (3.1.11) (omitting on the horizon) and (3.1.3) will be represented as

(3.1.8) begin (possible (by sight (perceive $(\mathrm{x}, \underline{\operatorname{ship}}(\mathrm{s}))))$ )

and (3.1.3) (with to me) and (3.1.4) as

(3.1.9) begin (possible (by sight (perceive (I, ship (s)))))

'emerge' and' surface' can also be represented by (3.1.7).

\subsection{Disappear, Reappear, and Behold}

The aspectual predicate begin in (3.1.7) suggests representations parallel to (3.7) with begin replaced by other aspectuals such as cease, continue, resume, etc. Thus we can represent disappear as 
(3.2.1) $\underline{\text { cease }}\left(\right.$ possible $\left(\right.$ by sight $\left(\right.$ perceive $\left.\left.\left.\left(x, \underline{P^{\prime}}(\mathrm{s})\right)\right)\right)\right)$

and 'reappear' as

(3.2.2) $\underline{\text { resume }}$ (possible $($ by sight $($ perceive $(\mathrm{x}, \underline{\mathrm{P}}(\mathrm{s})))))$

and possibly, 'behold' as

(3.2.3) $\underline{\text { continue }}\left(\right.$ possible $\left(\right.$ by sigh $\mathrm{t}\left(\right.$ perceive $\left.\left.\left.\left(\mathrm{x}, \underline{\mathrm{P}^{\prime}}(\mathrm{s})\right)\right)\right)\right)$

3.3 By replacing by sight by hearing in (3.1.7) we have

(3.3.1) begin (possible (by hearing perceive $(\mathrm{x}, \underline{\mathrm{P}}(\mathrm{s}))))$ )

but apparently, there is no lexical item corresponding to (3.3.1), although, in appropriate context, we can use appear as in (while listening to a piece of music)

(3.3.2) Suddenly, the cello appeared.

This seems to be true for some seeing verbs i.e., in a suitable context they can be used as hearing verbs (see also Section 5.5.3).

4. Hide

(4.1.1) John hid the jewels behind the mirror (under the table, in the drawer).

(4.1.2) John hid the jewels from Mary behind the mirror.

(4.1.3) John placed the jewels behind the mirror in order to hide them from Mary (so that Mary wouldn't see them).

(4.1.4) Mary wouldn't see the jewels because they (the jewels) are behind the mirror.

(4.1.5) Mary wouldn't see the jewels because the mirror hides them (is hiding them).

(4.1.6) Mary wouldn't see the jewels because the mirror is between her and the jewels.

(4.1.7) John is behind the tree, He is hiding from Mary.

(4.1.8) The tree hides (is hiding) John from Mary.

(4.1.9) John is hidden from Mary because he is behind the tree.

(4.1.10) John is hidden from Mary because the tree is between him and her.

(4.1.2), (4.1.3), and (4.1.4) are paraphrases. From (4.1.3) and (4.1.4) we see that place and behind as in

(4.1.11) place $(x, \underline{\text { behind }}(y, z))$

are two possible components in the final representation of hide. 
From (4.1.3) as well as from (4.1.4) and (4.1.5) it is clear that

(4.1.12) not (possible (by sight (perceive $\left.\left.\left(\mathrm{u}, \underline{\mathrm{P}^{\prime}}(\mathrm{s})\right)\right)\right)$ )

is also a component of hide and further (4.1.11) and (4.1.12) are linked by a causative(of intent) component (cf. (2.1.9). Hence, we may represent, hide as

(4.1.13) cause-intent (place $\left(\mathrm{x}, \underline{\text { behind }}(\mathrm{y}, \mathrm{z})\right.$, not (possible $\left(\underline{\text { by sight }}\right.$ (perceive $\left(\mathrm{u}, \underline{\left.\left.\left.\left.\left.\left.\mathrm{P}^{\prime}(\mathrm{s})\right)\right)\right)\right)\right)\right)}\right.$

From (4.1.6) and (4.1.10) we see that the appropriate relationship among 'mirror' , 'Mary', and 'jewels' in (4.1.6) and 'tree', 'Mary', and 'John' in (4.1. 10) is 'between' (p,q,r) ( $\mathrm{p}$ is between q and r). Since the 'loc' ('location') predicate has already been used before we can state this relationship as

(4. 1. 11) 'between' ('loc'(p). 'loc(q), loc (r))

Note further that

(4.1.12) 'place' (x, ‘behind'(y,z))

is redundant in the sense that 'place' can be eliminated but for the fact that in (4.1.11) 'place' is also an action predicate, i..e., we have the agent argument $\mathrm{x}$. One way to fix this is to introduce another causative component ('causative' (of result')) and a dummy action predicate 'do'.

Thus instead of (4.1.11) we will have (replacing 'behind' by 'between' )

(4.1.14) cause-result (do(x), between(loc(p), loc(q), loc(r)))

which can be roughly paraphrased as

x"s doing something causes $\mathrm{p}$ to be between $\mathrm{q}$ and $\mathrm{r}$.

between (loc $(\mathrm{p}\}, \operatorname{loc} .(\mathrm{q}\}, \operatorname{loc}(\mathrm{r}\})$

It might be argued that we have left out the 'intent' component, but. The dummy action predicate 'do' can be interpreted as an intentionality predicate (cf. Ross, 1970\}.

Hence, finally, we have the following representation for 'hide'.

(4.1.15) cause-intent(cause-result(do(x), between(loc (p), loc(q), loc(r))), not (possible (by sight (perceive $(\mathrm{u}, \mathrm{P}(\mathrm{s})))))$ )

(4.1.15) is a representation for (4.1.2) and (4.1.3) with $\mathrm{x}=$ John, $\mathrm{p}=$ mirror, $\mathrm{q}=$ Mary, $\mathrm{r}=$ jewels. For (4.1.4), (4.1.5) and (4.1.6) we have the same representation except that in (4.1.15) the first argument of 
'cause-intent', i.e., 'cause-result' is suppressed. According to our convention, the arguments of a suppressed argument are also suppressed. Hence 'do' and ' $x$ ' are also suppresses in this case.

(4.1.15) with 'cause-result' suppressed is one possible representation for (4.1.4), (4.1.5), and (4.1.6). But there is another possibility, namely, the case when no agent (argument $\mathrm{x}$ ) is involved at all. In this case the outermost predicate in (4.1.15) i.e., 'cause-intent' should be without the 'intent' component. It should be in fact 'cause-result'. Thus an alternate representation for (4.1.4), (4.1.5), and (4.1.6) is as follows

(4.1.16) cause-result (between (loc p), loc (q), loc (r)) not (possible (by sight (perceive (u, P(s))))) Where $\mathrm{p}=$ mirror, $\mathrm{q}=$ Mary, and $\mathrm{r}=$ jewels $=\mathrm{P}$.

Clearly, (4.1.16) is the appropriate representation for

(4.1.17) The hill hides the village.

(4.1.18) The village is hidden behind the hill.

Where $\mathrm{p}=$ hill, $\mathrm{r}=$ village $=\mathrm{P}$ and $\mathrm{q}$ is suppressed.

4.2 'conceal', 'secrete'. 'obscure' (v.t.), 'mask' and 'cover' (and possibly, 'screen') can also be represented by (4.1.15) and (4.1.16).

4.3 There does not seem to be a lexical item which can be considered as the aural equivalent of 'hide'. Perhaps, 'silence' (and possibly, 'gag') is a possible candidate ('I silenced the telephone'). (4.1.15) with 'by sight' replaced 'by hearing' is, however, not the appropriate representation of 'silence' because as we have seen before for 'hearing' verbs, locations are not explicitly involved. 'Silence' should be represented perhaps as follows.

(4.3.1) cause (do (x), not (possible (by hearing (perceive $(\mathrm{u}, \mathrm{P}(\mathrm{s})))))$ )

Of course, 'conceal' 'obscure', 'mask', etc. can be used as 'hearing' verbs in the appropriate context...

\subsection{Expose}

(5.1.1) He exposed himself to the enemy.

(5.1.2) He exposed himself to the enemy by being on the top of the hill.

(5.1.3) He exposed himself to the enemy by coming out. from behind the tree.

(5.1.4) He exposed himself to the enemy because of his coming out from behind the tree.

(5.1.5) She exposed the scars by wearing the dress.

(5.1.6) The scars were exposed because of her wearing' the dress.

(5.1.7) The scars were exposed because of the dress being on her.

(5.1.8) The dress exposed the scars.

Analogous to (4.1.15) and (4.1.16) 
(5.1.9) cause-intent (cause-result (do (x), between (loc(p), loc(q). loc(r) )), possible (by sight (perceive (u, $\mathrm{P}(\mathrm{s}))$ ))

(5. 1.10) cause-result.(between (loc (p), loc(q),(r) ), possible (by sight (perceive (u, P(s)))))

are the two representations for 'expose'. (5.1. 2) - (5.1. 6) can be represented by (5.1.9) and (5.1.1) and (5.1.7) by (5.1.9) with 'cause-result' suppressed. (S.1.8) and also (5.1.7) can be represented by (5.1.10).

5.2 (5.1.9) and (5.1.10) can also represent 'display', 'reveal', 'disclose', 'exhibit'. 'show', 'uncover' unmask', 'flaunt' (?), etc.

5.3 Apparently, there is no lexical item which is the aural counterpart of 'expose'.

\section{Glance}

The 'aim' predicate in (2.1.9) can be 'modified' (modulated) by a durative predicate such as 'momentary' (or 'sudden') giving us the representation for 'glance'.

(6.1) 'cause-intent' (by sight (momentary (aim(x, loc(y). possible (by sight (perceive (x, P(s))))

Note that both 'by sight' and 'momentary' operate on 'aim' in (6.1). The order in which we have represented them is quite arbitrary. The fact that we are forced to choose an order is due the particular formal character of the representation we have chosen, namely, the operator and operand notation. The same would be true if we had chosen the dependency representation or the phrase structure representation (see Section 5.5). (6.1) can also represent 'peek', 'glimpse', and 'scan' (in one of its senses),

Instead of 'momentary' in $(6,1)$ if we choose 'continual' (or 'continuous'), we get the representation for 'stare', 'gaze', 'gape', 'regard', 'glare', and 'glower' can be similarly represented.

'There is no lexical item corresponding to 'intermittent', i.e., something equivalent to 'look intermittently'.

It is possible to have the durative predicate on see (v.i), also, i.e., on 'perceive' in (1.3.9). Thus

(6.3) 'possible' ('by sight' (momentary (perceive(x, P(s)))))

(roughly paraphrased as 'seen momentarily') is a representation of 'flash' as in 'the car flashed by'.

There are no lexical items corresponding to 'intermittent' or 'continual' in (6.3), i.e. correspond to 'seen intermittently' or 'seen continuously (visible all the time). 
'aim' in (2.1.9) can be modulated by a manner predicat.es also. For example, predicates such as 'careful' ('careful manner'), 'attentive' ('attentive manner'), etc. would give us the representations for 'peer', 'regard', 'peep', gaze', and 'stare'. Note that 'gaze' and 'stare' have now two representations, one corresponding to 'continual' and the other corresponding 'attentive manner' or 'intent manner'. It is interesting to note that these two predicates are not: completely independent; one cannot look at something carefully or attentively by looking at it only momentarily. It would be also interesting to check whether these durative and manner predicates are correlated in this manner in other semantic domains.

If we replace the second argument of 'aim' in (2.1.9) by a set of locations and modulate 'aim' b a set of locations and modulate 'aim' by 'one by one (in a sequence)' we perhaps have the representation for 'scan' in its technical sense. In another sense it has the same representation as 'glance' ('I scanned the headlines').

We can also have manner predicates on 'see' (i.e., on 'perceive' in (2.1.2)) such as 'distinct manner', 'with effort', etc. Thus we will obtain representations for 'discern', and 'espy'. 'see' with action representation (as in (1.2.19) can be similarly modified but not 'see' with a factive representation (1.2.26), 'I espied a snake' crawling', * I espied that the snake was crawling').

There are no aural equivalents for 'glance','stare', 'gaze'. etc., i.e., we have no verbs corresponding to 'listen momentarily', 'listen continually', 'listen attentively', 'to be heard momentarily' 'listen continually', 'listen attentively', 'be heard momentarily', etc. Moreover, these verbs cannot be used as 'hearing verbs' in an appropriate context, just as 'appear' can (see (3.3.2).

When it comes to modulating the basic predicates in the representation of 'hear' and 'listen' (equivalents of 'see' and 'look', respectively) the lexicon appears to be extremely deficient.

\section{7. 'Blind'}

(7.1) The storm blinded me.

(7.2) The storm was blinding.

(7.3) Snow blinded me,

(7.4) (Falling of, Blowing of) snow blinded me.

(7.5) Dust blinded me.

(7.6) (Blowing of dust) blinded me.

'Blind' is like 'hide' as in (4.1.16) ('the hill hides the village" ) except that the first argument of causeresult is now an action or event predicate ('act' in (1.2.19)). Thus

(7.7) cause-result (act (Q ( ), not (possible (by sight (perceive(x, $\mathrm{P}(\mathrm{s})))))$ )

is a representation for 'blind' where $\mathrm{Q}$ is an action or event predicate, For words such as 'storm', 'snow', 'rain', etc. Whenever not explicitly present, an appropriate action or event predicate will be assumed such as 'fall', 'blow', 'happen', 'occur', etc. 
'blur' and 'darken' can also be represented as (7. 7) ('the room darkened', the drawing of the curtains darkened the room', 'the drawing of the curtains made it not possible to see in the room', 'the curtains darkened the room'). 'dazzle' has the same representation except that in this case we should modulate the second argument of (7.7) by a durative predicate 'momentary', i.e., the representation will be

(7.8) cause-result (act (Q ( ), momentary ( $\operatorname{not}(\ldots$

Although 'darken' is a 'seeing' verb, the case for 'brighten' is not so clear. 'Brighten' does not necessarily have the sense of 'making it easier (more possible?) to see'.

For 'hide', 'silence' is a possible aural equivalent. 'Blind' etc. are like 'hide'. However, there are no aural equivalents for them ('jam' ??, 'jar' ??) and as in the case of 'glance', etc. these verbs cannot be used as 'hearing verbs' (a possible exception is 'blur').

8. Fade

By 'modulating' the begin predicate in (3.1.7) by a manner predicate such as 'slow' (gradual ?) we can represent 'fade' as well as 'fade-in' by

(8.1) slow (begin (possible (by sight (perceive $(\mathrm{x}, \mathrm{P}(\mathrm{s}))))$ ))

and 'fade-out' from (3.2.1) by

(8.2) slow (cease (possible (...)

With 'rapid' (or 'sudden') on (3.2.1) we have

(8.3) rapid (cease (possible $(\ldots$

which is the representation for 'vanish'. There is no lexical item corresponding to 'rapid' on (3.1.7), i.e., something equivalent to 'rapidly come into sight or 'burst forth into sight'. Also it is not possible to modulate 'reappear' (3.2.2) or 'behold' (3.2.3) by these manner predicates.

'peep' in one of its senses can also be represented by (8.1) as in 'stars peeped through the clouds).

9. 'Notice'

'Notice' is almost like 'see' (Section 1.1). It has representations (1.1.2), (1.2.19), and (1.2.26) but not (1.2.30) and (1.3.9). For 'notice' the factive reading (1.2.26) sounds much better with 'see' instead of 'notice'.

(1.2.26) 'by sight' ('perceive' ( $\mathrm{x}$, 'fact' (Q))))

(9.1) I saw him smiling at her.

(9.2) I noticed him smiling at her. 
? (9.3) I saw the brand of cigarettes he was smoking.

(9.4) I noticed the brand of cigarettes he was smoking.

“Observe' and 'watch' (and possibly, 'eye') can be similarly represented by (1.2.2), (1.2.19), and (1.2.26). Also (2.1.9) with 'careful' on the predicate 'aim' will be another representation for 'observe' and 'watch' (see Section 6).

There is a syntactic difference between 'see' and 'watch' (and perhaps also 'notice'). However, it does not seem relevant for our purpose,

(9.5) We saw him cross the street (crossing the street).

(9.5) has a passive but not (9. 7) below (Palmer, 1968).

(9.6) He was seen to cross the street (crossing the street).by us.

(9.7) We watched him cross the street (crossing the street).

*(9.8) He was watched to cross the street (crossing the street).

'spot' also has representations $(1,2,2)$ and $(1,2,19)$ but not the factive $(1,2,26)$, In $(1,2,19)$

(1.2.19) 'by sight' ('perceive' ( $\mathrm{x}$, 'act' (Q ( ))))

The predicate 'act' covers, among other things, both ongoing and completed activities. For 'spot' we can only have an ongoing activity (Vendler, 1967).

(9.9) We spotted him crossing the street.

*(9.10) We spotted him cross the street.

'Sight' has the representation (1.2.2) and possibly also (1.2.19) with the qualification mentioned above for 'spot'.

(9.11) We sighted the ship.

(9.12) We sighted the car turning into the driveway.

(9.13) We sighted the car turn into the driveway.

'View' and 'survey' can be represented by (1.2.2) and (1.2.19). However, in (1.2.2) there is a restriction on P. P denotes objects spread out in space.

(9.14) We viewed the parade (procession, landscape, etc.).

*(9.15) We viewed a cat.

'View" and 'survey' in the sense of 'examine' and 'inspect' will be discussed in Section 5.4

'Witness' can be represented by (1.2.19) and the factive (1.2.26) but not by (1.2.2). 
(9.16) We witnessed him receiving the diploma.

(9.17) We witnessed an accident.

(9.18) We witnessed a cat.

Since all these verbs essentially have the representation for 'see', they can be used as 'hearing' verbs in an appropriate context.

10 'Examine'

In (2.1.9) (representations for 'look at') 'by sight' operates on both 'aim' and 'perceive' (allowing the possib1ity of factoring it out of both the arguments of 'cause-intent). We can represent 'examine' by (2.1.9) by deleting the second occurrence of 'by sight', replacing 'perceive' possibly by 'find ('detect', 'determine', etc.) and adding 'careful' on 'aim' as in Section 5.4.

(10.1) 'cause-intent (by sight (careful (aim(x, loc (y)))), possible (find (x, P(s))))

The similarity of 'examine' and 'look at' can be seen in the following.

(10.2) I examined the surface for cracks.

(10.3) I examined the surface in order to find (detect) cracks.

(10.4) I carefully looked at the surface in order to find the cracks.

(Note that 'find' is not a 'seeing' verb but 'find' may have 'see' as an optional component (see Section 5.3.1). This justifies to some extent our replacing 'perceive' in (2.1.9) by 'find'.)

There is a difference between 'examine' and 'look at', however.

(10.5) I looked at $\mathrm{X}$ in order to see $\mathrm{Y}$.

In (10.5) either $\mathrm{Y}$ is not the same as $\mathrm{X}$ as in

(10.6) I looked at the sky in order to see the plane.

or it is the same as $\mathrm{X}$ as in

(10.7) I looked at the tree.

But for 'examine' $\mathrm{Y}$ is never the same as $\mathrm{X}$..

*(10.8) I examined the cracks in order to find the cracks.

(10.9) I examined the cracks. 
(10.9) is always interpreted as 'I examined the cracks in order to find (detect) something else (see also Sibly, 1955).

'Inspect', 'scrutinize', 'view', 'survey', and 'look for' can be similarly represented. All these verbs can be used as 'hearing' verbs in an appropriate context.

\section{1. 'Look for'}

(11.1) I am looking for my glasses.

(11.2) I am trying to flnd my glasses.

(11.3) I am looking around in order to find (see ??) my glasses.

This suggests that 'look for' can also be represented by (10.1) (without the component 'careful') and possibly replacing 'loc' the second argument. Of 'aim' by a set of locations (see 'scan' in Section 6). Note that the second argument of 'aim' does not necessarily have to be a set of locations.

(10.4) I looked for my glasses under the table (on the shelf).

Perhaps this second argument should be something like 'region', even in the representation for 'look at'.

Similarly, 'search' and 'seek' can be similarly represented (see also Sibley, 1955). These verbs can also be used as 'hearing' verbs in an appropriate contexts.

(Sentences containing 'look for' etc. are sometimes called intentional because they use a name or a description in such a way that "neither the sentence nor its contradiction implies either that there is or that there isn't anything to which the description truly applies" (Chisholm, 1957)).

\subsection{Summary:}

\subsubsection{List of predicates used in Section 5.4}

perceive, by sight, make sure, act, fact, state, aim, location, between, possible, not, cause-intent, causeresult, do, begin, cease, resume, continue, momentary, continual, intermittent, careful (manner), intent (manner), sly(manner), distinct(manner), one by one (in sequence), slow, rapid, find

Out of the two components 'perceive' and 'by sight', 'perceive', of course, would be needed for other verbs of 'seeing'. Most of the other components will show up in the analyses of other semantic domains, e.g., motion verbs, communication verbs, etc.

\subsubsection{List of representations:}

(1.1.2) by sight (perceive (x, $\mathrm{P}(\mathrm{s}))$ )

(1.2.10) by sight (perceive $(\mathrm{x}$, act $(\mathrm{Q}(\mathrm{)})))$
P: classifier or identifier

Q: action predicate 
(1.2.26) by sight (perceive ( $\mathrm{x}$, fact (Q))))

(1.2.30) by sight (make sure ( $\mathrm{x}$, fact $(\mathrm{Q}(\mathrm{)})))$

(1.3.9) possible by sight perceive $(\mathrm{x}, \mathrm{P}(\mathrm{s})))$ )

(2.1.9) cause-intent (by sight (aim (x, loc (y)), possible (by sight (perceive (s, P(s))))

(2.2.19) by sight (perceive $(\mathrm{x}$, state $(\mathrm{R}(\mathrm{)})))$ R state predicate

(3.1.7) begin $((1.3 .9))$

(3.2.1) cease $((1.3 .9))$

(3.2.2) resume $((1.3 .9))$

(3.2.3) continue ((1.3.9))

(4.1.15) cause-intent (cause-result (do (x), between (loc (p), loc (q), loc r)), not ((1.3.9))

(4.1.16) cause-result (between (loc (p), loc (q), loc r, not ((1.3.9)))

(5.1.9) Same as (4.1.15) but without 'not'

(5.1.10) Same as (4.1.16) but without 'not'

(6.1) cause-intent (by sight (momentary (aim (x, loc $(y))$, possible (by sight (perceive (x, $\mathrm{P}(\mathrm{s})))))$

Similar representations with 'continual', 'intermittent', replacing 'momentary' in (6.1). Also similar representations with manner predicates such as 'careful', 'intent', 'sly' etc. instead of 'momentary' in (6.1).

(7.7) cause-result (act $(\mathrm{Q}(), \operatorname{not}(1.3 .9))) \mathrm{Q}$ : action or event predicate

(7.8) cause-result (act (Q). not ((1.3.9))) Q: action or event predicate

(8.1) slow $((3.1 .7))$

(8.2) slow $((3.2 .1))$

(8.3) rapid ((3.1.7))

(10.1) cause-intent (by sight (careful (aim (x, loc (y)))), possible (find(x, P(s))))

These representations show how the components in Section 5.5.1 are composed. One could easily write rules for composition (i.e., a grammar) which will generate precisely the set of representations in Section 5.5.2 and there will be many different ways of writing this grammar. We will not do this, however, as the list in Section 5.5.2 is by no means complete and also it may need to be revised considerably.

The particular way in which we choose to write the grammar will affect the formulations of the rules which allow us to collapse a set of predicates into a composite predicate which is then lexically realized, if possible, e.g., a predicate raising rule (generalized as in Section 2.4) for a phrase structure grammar, a conflation rule (Section 2.4) for a dependency grammar or an operator-operand representation, etc. These collapsing rules in turn affect the formulation of a possible theory of accidental and systematic lexical gaps.

When two predicates, say, P and Q. modify a third predicate, say, R we are forced to choose a certain order in which $\mathrm{P}$ and $\mathrm{Q}$ are introduced in the derivation. This is true both in the phrase structure and the dependency (or the operator-operand) representations. Sometimes this creates pseudo-problems. For example, in (1.3.9) the order in which the two components 'perceive' and 'possible' appear is really not 
significant. The order given in (1.3.9) seems natural in one sense because it allows us to derive (1.3.9) from (1.1.2) by letting 'possible' operate on (1.1.2). On the other hand the opposite order as in

$\left(1.3 .9^{\prime}\right)$ by sight (possible (perceive $\left.(\mathrm{x}, \mathrm{P}(\mathrm{s}))\right)$ )

can also be justified as follows. Almost all the representations in Section 5.5.2 can be 'generalized' to the nonvisual sense by simply deleting the 'by sight component'. (1.3.9) when hen generalized in this way will lead to a representation with a 'gap' and we would need rules which will close this gap. The net effect of all this will be that 'possible' will now operate on 'perceive'. In (1.3.9') deleting 'by sight' does not lead to a gap and we will not need any gap-closing rules. Of course, a more appropriate solution is to adopt a representation such that we are not forced to choose a specific order i.e., we 'by sight' and 'possible' both operate on perceive independently. Appropriate predicate collapsing rules would have to be formulated for such a representation also.

Incidentally, adopting (1.3.9') would allow us to factor by 'by sight' out of the first and the second arguments of cause-intent in (2.1.9) and even move it beyond 'cause-intent', i.e.

(2.1.9') by sight (cause-intent (aim ..., possible (perceive ...))

Now 'by sight' can be deleted without a gap, leading to a representation of 'look at' in the non-visual sense.

The choice of a suitable representation and the corresponding formulation of a suitable predicate collapsing rules is still very much an open problem.

\subsubsection{Lexical gaps:}

In Section 5.4 we have noted a number of lexical gaps both in the context of verbs of 'seeing' and also in the context of extending the representations for the verbs of 'seeing' the verbs of 'hearing'.

In the context of the verbs of 'seeing' there appear to be gaps when one tries to combine the durative and manner predicates with the basic representations, viz., (1.1.2), (1.3.9), and (2.1.9) (see Sections 5.4 -6, 7, and 8 in Section 5.4)

The more interesting gaps arise when the 'seeing' representations are carried over to 'hearing' (see 2, 3, 4, 5, 6 and 7 in Section 5.4). Many of these gaps reflect the fact that 'hearing' verbs do not involve the directional as well as the locational components explicitly (see 2, 3, 4, 5, 6, and 7 in Section 5.4). The inability of many durative and manner predicates to combine with the basic representations (i.e., representations for hear and listen) also leads to gaps just as it does in the case of 'seeing' verbs. The 'hearing' gaps are much 'wider' in this case as compared to the 'seeing' gaps', for example, no durative predicates at all are allowed on 'listen' (see 6 and 7 of Section5,4),

Whether we should call all these gaps accidental or systematic at present is difficult to say. We really do not have at present any theory accidental and systematic gaps for the lexicon. We could, of course, call all 
these gaps accidental because they correspond to combinations of components which are permitted by the rules of composition (not explicitly stated but, implicit in the set of representations in Section (5.5.2) and for which there are no corresponding lexical items. (We are assuming here that a predicate merging rule such as predicate raising or conflation is available for merging only those predicates ", which are related in a certain way, e.g., a predicate can be merged with other predicates which are its immediate descendants in a dependency representation. (The precise nature of this rule is not relevant here.) But this is not a very convincing explanation because it assumes that our representations and the implied rules of composition can be independently justified, which is very doubtful. The situation is perhaps the other way round. The ability to predict and explain the lexical gaps in terms of a representation should be considered as a justification for that representation (see also Ross, 1971).

What about the gaps that would result if we try to combine the 'seeing' and 'hearing' representations i.e., verbs which would simultaneously have the sense of both 'seeing' and 'hearing'? English certainly does not have such a verb. I would guess that such verbs, if they exist at all, must be quite rare and highly restricted in their use. Apparent.ly, in, Japanese, there is a verb meaning 'see-hear (or 'look-listen') but it is used only in the context: of television programs in order to distinguish them from radio programs.

It is clear that similar analyses for 'seeing' and 'hearing' verbs in several different languages would be most valuable in the study of lexical gaps in the semantic domain of perception verbs.

\section{Other verbs of perception:}

Throughout Section 5 we have seen to what extent the representations for 'seeing' verbs can be carried over to the 'hearing' verbs. We will now comment very briefly on some non-visual and non-aural verbs of perception.

6.1 Corresponding to the 'see-look' and 'hear-listen' pairs we have

see hear smell feel taste

look listen sniff touch taste, savor

6.2 Corresponding to 'appear' ('the ship appeared on the horizon') for visual perception and corresponding to 'sound'( 'the bell sounded sharp') for aural perception, we have

appear sound smell feel taste

'the rose smelt nice' 'the surface felt smooth' 'the wine tasted sweet'

6.3 There are corresponding nominal forms except for visual perception.

?? look ?, sound, smell, feel, taste 
(The bell has a (sharp) sound, T:he rose has a (nice) sme11, The surface has a (smooth)fee1, The wine has a (sweet) taste)

Is this an accidental or systematic gap? (See also Warnock, 1967.)

6.4 Both 'see' and 'hear' take propositional complements. 'smell' and 'feel' also take some propositional complements; however, 'taste' does not any propositional complements.

(6.4.1) I smelt the roast burning.

?? (6.4.2) I smelt the roast burn.

?(6.4.3) I smelt that the roast was burning.

(6.4.4) I felt the cat crawling into the bed.

(6.4.5) I felt the cat crawl into the bed.

(6.4.6) I felt that the cat was crawling into the bed.

With these remarks it is easy to see which representations from the list in Section 5.5.2 carry over to these verbs of perception. 


\section{References:}

1. Anderson, J.M. (1971), The Grammar of Case, Cambridge University Press, Cambridge.

2. Anscombe, G.E M. (1965), "The intentionality of perception: a grammatical feature", in R.J. Butler (ed.) Analytical Philosophy, Second Series, Oxford University Press, Oxford, pp. 158-80.

3. Austin, J. (1962), Sense and Senibilia, Oxford University Press, Oxford, (reconstructed from the Manuscript notes by G.J. Warnock.

4. Bach, E. (1968), "Nouns and Nounphrases", in E.Bach and R.T.Harms, Universals in Linguistic Theory, Holt, Rinehart and Winston, Inc., New York, pp. 91-124.

5. Bierwisch, M. (1970), "Semantics", in J. Lyons (ed.), New Horizons in Linguistics, Penguin Books, Harmondsworth, England.

6, Bierwisch, M. (1971), "On classifying semantic features", in D.D.Stejnberg and L.A. Jakobovits (eds) Semantics, Cambridge University Press, Cambridge, pp. 410-435.

7. Chisholm, R.M. (1957), Perceiving, Cornell University Press, Ithaca.

8. Chomsky, N. (1965), Aspects of the Theory of Syntax, M.I.T Press, Cambridge.

9. Davidson,D, (1967), "The logical form of action sentences", in N. Rescher (ed.), 'The Logic of Decision and Action", University of Pittsburg Press, Pittsburg, pp. 81-120.

10. Dixion, R.M.W.(1971), "A method of semantic description", in D.D. Steinberg and L.A. Jakobovits(eds.), 'Semantics', Cambridge University Press, Cambridge, pp. 436-471.

11. Fraser, B. (1970), "Some remarks on the action nominalizations In English", in R.A.Jacobs and P.S.Rosenbaum (eds.), "Readings in English Transformational Grammar", Ginn and Company, Waltham, Mass., pp. 83-98.

12. Fi1 1 more, C.J. (1968), "Lexical entries for verbs", in "Working Papers in Linguistics", No.2, The Ohio State University, Columbus, pp. 1-29.

13. Fillmore C.J. (1971), "Some problems for case grammar", in "Working Papers in Linguistics" No.10, The Ohio State University, Columbus, pp. 245-265.

14. Fillmore, C.J. (1971), "Verbs of judging: An exercise in semantic description", in E. Each and R.T. Harms (eds.), 'Universals in Linguistic Theory' Holt Rinehart, and Winston, Inc. New York, pp.91-124.

15. Gruber, J.S. (1965), Studies in Lexical Relations, Ph.D. Dissertation, M.I.T. Cambridge, Mass.

16. Gruber, J.S. (1967), "Look and See”, Language, vol. 43, no.4, pp. 937-954.

17, Harris, Z.S, (1965), “Transformational Theory”, Language, vol. 41, pp. 363-401.

18. Harris, Z.S. (1968) Mathematical Structures of Language, John Wiley \& Sons ( Interscience Publishers), New York.

19. Harris, Z.S. (1968) "Two Systems of Grammar; Report and Paraphrase" in Z.S. Harris, Structural and Transformational Linguistics, D. Reidel Publishing Co., Dordrecht, Holland.

20. Hintikka, J. (1969), Mode1s and Modalities, D. Heidel Publishing Co., Dordrecht., Ho11and.-

21. Lakoff, G. (1971), "On generative semantics", in D.D,Steinberg and L.A. Jakobovits (eds), Semantics, Cambridge University Press, Cambridge, pp.. 232-296.

22, Lee, P,G. (1969), "Do from Occur", in Working Papers in Linguistics, No: 3, 1.SLui_st.ic§., No, 3, The Ohio State University, Columbus, PP. 1-21.

23. Miller, G.A. (1972 a), "English verbs of motion:: a case study in semantics and lexical memory", in A.W. Melton and E. Martin (eds.), Coding Processes in Human Memory (New York), in press. 
24. Miller, G.A. (1972 b.) "Lexical Memory", Proe. American Philosophical Society, vol. 116, no. 2, pp. 140-144.

25. Palmer, F.R. (1968), A Linguistic Study of English Verbs, University of Miami Press, Coral Gables, Florida.

26, Parsons, T. (1970), "Some problems concerning the logic of grammatical modifiers", Synthese, vol. 21, pp. 321-334.

27. Pitcher, G. (1971), A Theory of Perception, Princeton University Press, Princeton.

28. Postal, F. (1970), "'The surface verb 'remind”, Linguistic Inquiry, vol. I, pp. 37-120.

29. Ross, J. R. (1971), "Act", in ??

30. Ryle, G. (1949), The Concept of Mind, Hutchinson, London.

31. Schank, R.C. (1972), "Conceptual dependency: a theory of natural language understanding", Journal of Cognitive Psychology, vol 3., in press.

32. Sibley, F.N. (1955), "Seeking, scrutinizing, and seeing”, MIND, vol.64, pp. 455-78 (also in G. J.

Warnock (ed.), The Philosophy of Perception, Oxford University Press, Oxford (1967).

33. Smith, c. (1964), "Determiners and relative clauses in a generative grammar of English", Language, vol. 40 , pp. 37-52.

34. Vendler, Z. (1957), "Verbs and Times", The Philosophical Review, vol.66, pp. 143-160 (also in Z.

Vendler, 'Linguistics and Philosophy', Cornell University Press, Ithaca, (1967).

35. Warnock, G.J. (1967), "Introduction”, in G.J. Warnock (ed.), “The Philosophy of Perception”, Oxford University Press, Oxford, pp. 1-7.

36, Zwicky, A.M.(1971), "Linguistics as Chemistry, the substance theory of semantic primes", Working Papers in Linguistics' No. 8, The Ohio State University Press, Columbus, Ohio, pp. 111-135. 